\title{
Kinetics of Hydrogenation and Hydrogenolysis of 2,5-Dimethylfuran over Noble Metals Catalysts under Mild Conditions
}

\author{
Ying Lin Louie, Joseph Tang, Alexander M. L. Hell, and Alexis T. Bell* \\ Energy Biosciences Institute \\ and \\ Department of Chemical and Biomolecular Engineering \\ University of California \\ Berkeley, CA 94720
}

Submitted to

Applied Catalysis B General

May 11, 2016

Keywords: Dimethylfuran, Hydrogenation, Platinum, Ring-opening, Kinetic models 


\section{ABSTRACT:}

Ketones, derived via the selective ring-opening hydrogenation of biomass-derived furanic compounds, are useful synthons for the production of fuels and lubricant. In this study, 2,5dimethylfuran (DMF) was used as a model to investigate the liquid-phase hydrogenation of substituted furans over noble metals. The activity and selectivity of carbon-supported $\mathrm{Pt}, \mathrm{Pd}, \mathrm{Rh}$, and $\mathrm{Ru}$ were compared under identical conditions. Pt/C exhibited the highest activity and selectivity for C-O bond hydrogenolysis, whereas all other catalysts exhibited a high selectivity for ring hydrogenation to form 2,5-dimethyltetrahydrofuran. The reaction kinetics were measured in detail for liquid-phase hydrogenation of DMF over $\mathrm{Pt} / \mathrm{C}$, under conditions that excluded the effects of internal or external mass transfer $\left(333 \mathrm{~K}-363 \mathrm{~K}, \mathrm{p}_{\mathrm{H} 2}=0.41-0.69 \mathrm{MPa}\right)$. A reaction mechanism is proposed to explain the parallel formation of 2,5dimethyltetrahydrofuran, 2-hexanone, and 2-hexanol. This mechanism is consistent with what is known about the adsorption of DMF on Pt, and explains why ring opening occurs directly from adsorbed DMF and not via secondary reaction of 2,5-dimethyltetrahydrofuran. The kinetics of DMF hydrogenation are well represented by the mechanism and the assumption of noncompetitive adsorption of organic species and hydrogen atoms. The step involving $\mathrm{C}-\mathrm{O}$ bond cleavage of the aromatic ring had the highest activation energy, $48.3 \mathrm{~kJ} / \mathrm{mol}$, and is favored over the steps involving $\mathrm{C}=\mathrm{C}$ bond hydrogenation of the furan ring at elevated temperatures and low $\mathrm{p}_{\mathrm{H} 2}$. The reaction kinetics reveal that DMF hydrogenation can be tuned to produce 2-hexanone with $92 \%$ selectivity at $100 \%$ conversion under relatively mild liquid phase conditions (0.41MPa, 393K). 


\section{Introduction}

One of the strategies for transforming the hemicellulosic and cellulosic fractions of biomass into valued chemical products and fuel additives is hydrolysis of these polysaccharides to their respective sugar monomers, primarily xylose and glucose, followed by dehydration to produce furfural and 5-hydroxymethylfurfural, respectively [1]. Furanic compounds derived in this manner retain all of the monosaccharide carbon and contain roughly half as much oxygen, and can be converted to jet, diesel, and lubricants via aldol condensation $[2,3]$, oligomerization $[4,5]$, and hydroalkylation [6-8]. The resulting products are $\mathrm{C}_{9}-\mathrm{C}_{21}$ furanics, which can, in turn, be converted to ketones or alcohols by partial hydrogenation, or to hydrocarbons by hydrodeoxygenation. Aldehydes and ketones sourced in this manner readily undergo $\mathrm{C}-\mathrm{C}$ coupling via aldol condensation [2, 3] or self-trimerization to produce diesel and jet fuel [9]. For these reasons, there is considerable interest in understanding the activity and selectivity of catalysts that can be used for the hydrogenation of furanic compounds, and in particular, what factors govern the selectivity for furan ring saturation versus furan ring hydrogenolysis to produce ketones, aldehydes, and alcohols.

Vapor-phase hydrogenation of low molecular weight furanics, such as 2-methylfuran (MF), 2,5-dimethylfuran (DMF), and furfural (FUR), has been investigated over Pd, Pt, Ni, Cu, and Co catalysts at moderate conditions $(363 \mathrm{~K}-473 \mathrm{~K}, 0.1 \mathrm{MPa})[6-8,10-13]$. The products observed include partially or fully saturated derivatives of tetrahydrofuran and ring-opened products, such as alcohols, ketones, and aldehydes. Higher selectivity toward ring-opened products has been observed over Pt, whereas higher selectivity to tetrahydrofuran products has been reported over Pd [14-17]. Several studies have also observed a greater degree of ring opening, cracking, and decarbonylation when hydrogenation was performed at temperatures 
above 493K [12-15]. Finally, application of harsher conditions $\left(573 \mathrm{~K}-673 \mathrm{~K}, 7-20 \mathrm{MPa} \mathrm{H}_{2}\right)$ during hydrogenation over noble metals resulted in complete oxygen removal and the production of hydrocarbons $[6,18,19]$.

Relatively little is known about the reaction network by which the hydrogenation of furanic compounds occurs and in particular, the mechanism responsible for the formation of ring-opened products, i.e., ketones and alcohols. Kliewer et al. [13] and Runnebaum et al. [20] have proposed that over Pt, the formation of butanal and butanol results from hydrogenolysis of tetrahydrofuran formed by ring hydrogenation of furan. Similarly, Kang et al. have suggested, based upon isotopic-labeling studies, that $\mathrm{C}-\mathrm{O}$ bond hydrogenolysis occurs at the etheric $\mathrm{C}-\mathrm{O}$ bonds and not at the aromatic $\mathrm{C}-\mathrm{O}$ bonds of the furan ring during vapor-phase hydrogenation of DMF and MF over Pt and Pd catalysts [16]. On the other hand, studies of liquid-phase hydrogenation of alkylfurans (MF, DMF) suggest that ring hydrogenolysis occurs directly from the alkylfuran substrates based on the observation of significantly lower activity toward ring opening in tetrahydrofuran derivatives versus alkylfurans $[15,17,21]$. The 2-methylfuran intermediate formed during hydrodeoxygenation of furfural over $\mathrm{Pt} / \mathrm{C}$ has been reported to produce 2-methyltetrahydrofuran and 2-pentanol in parallel, but intrinsic rate data could not be obtained due to the occurrence of mass transfer effects in the liquid phase flow system used for the study [22].

Although direct ring scission of the aromatic furan has been suggested by the aforementioned studies, few have addressed the mechanism and kinetics involved. In a recent study by Vlachos and coworkers, isotopic labeling and density functional calculations were used to show that certain metals, such as $\mathrm{Ru}$, activate the furan ring, resulting in scission of the C-O bond in 2-methylfuran [23]. Although the proposed mechanism supports ring opening of the 
furan moiety at the metal site, this reaction was only found to occur at unsubstituted $\alpha$ carbon positions; consequently, the mechanism by which ring opening occurs for highly substituted compounds such as DMF remains uncertain. In addition, the pathways responsible for preferential formation of ketones versus alcohols following $\mathrm{C}-\mathrm{O}$ hydrogenolysis of substituted furans have not been clearly defined. Corma et al. have reported 100\% yield of 2-hexanone upon gas-phase hydrogenation of DMF over Pt/C at 623K [6]. By contrast, Smith and Fuzek have reported exclusive production of butanol and 2-hexanol during liquid-phase hydrogenation of furan and DMF, respectively, over platinum oxide in acetic acid at 308K, $0.14-0.41 \mathrm{MPa}$, and Aliaga et al. have observed the formation of $\mathrm{C}_{5}$ and $\mathrm{C}_{6}$ alcohols but no ketones during gas phase hydrogenation of MF and DMF, respectively, over supported Pt nanoparticles [12]. Therefore, the mechanism by which furanic compounds are hydrogenated appear to be strongly influenced by the reaction conditions employed as well as the catalyst composition [15].

Given the current level of knowledge, systematic studies that consider the kinetics of all reactions involved in the hydrogenation of furanic compounds (ring opening, ring saturation, $\mathrm{C}=\mathrm{O}$ hydrogenation) are needed in order to obtain a fundamental understanding of the molecular relationships between catalyst properties and their activity and selectivity. The aim of this study was to elucidate the reaction mechanism and kinetics for the hydrogenation of 2,5-dimethylfuran (DMF) over noble metals. DMF was chosen as a model for furanic compounds derived from biomass. To this end, we investigated the influence of catalyst composition and reaction conditions on the product selectivity and the rate parameters for both ring hydrogenolysis and ring saturation.

\section{Experimental}

\subsection{Materials}


2,5-Dimethylfuran, 2,5-dimethyltetrahydrofuran, 2-hexanone, 2-hexanol, and nonane were purchased from Sigma-Aldrich. Hydrogenation catalysts, including Pd/carbon (10 wt\%), $\mathrm{Pt} /$ carbon (5 wt\%), Ru/carbon (5 wt\%) and $\mathrm{Rh} /$ carbon (5 wt $\%$ ), were used as received from Sigma-Aldrich, USA after drying overnight at $383 \mathrm{~K}$ to remove residual moisture. All oxide supports, $\gamma-\mathrm{Al}_{2} \mathrm{O}_{3}, \mathrm{TiO}_{2}$ (anatase), and $\mathrm{NbOPO}_{4}$ (niobium phosphate, $\mathrm{CBMM}$ ) were calcined at $573 \mathrm{~K}$ for $3 \mathrm{~h}$ prior to dispersion of $\mathrm{Pt}$.

\subsection{Catalysts Synthesis}

To investigate the effects of support composition of the catalyst on the rates of DMF and 2-hexanone hydrogenation, Pt was dispersed onto oxide supports either by strong electrostatic adsorption (SEA) or incipient wetness impregnation (IWI) methods. SEA allows for the preparation of highly dispersed metal nanoparticles with particle size controlled by varying the calcination temperature post adsorption [24]. Supports with a low PZC, such as $\mathrm{NbOPO}_{4}$, were slurried in $80 \mathrm{~mL} \mathrm{H}_{2} \mathrm{O}$ and the $\mathrm{pH}$ was increased to 9.5 by addition of ammonia hydroxide. A predetermined loading of tetraamineplatinum(II) nitrate $\left(\mathrm{Pt}\left(\mathrm{NH}_{3}\right)_{4}\left(\mathrm{NO}_{3}\right)_{2}\right)$, was dissolved in $10 \mathrm{~mL}$ of $\mathrm{H}_{2} \mathrm{O}$ and added to the slurry. For supports with higher PZC such as $\gamma-\mathrm{Al}_{2} \mathrm{O}_{3}$, the pH of the slurry was adjusted to 4.4 using $\mathrm{HCl}$ and chloroplatinic acid $\left(\mathrm{H}_{2} \mathrm{PtCl}_{6}\right)$ was used as the anionic precursor. After stirring for $1 \mathrm{~h}$, the impregnated solid was washed, filtered and dried overnight at $373 \mathrm{~K}$ under flowing air. All filtrate was collected and analyzed via ICP-MS to determine the final loading of Pt on supports. All SEA preparation procedures resulted in $<4 \%$ of metal precursor remaining in the filtrate, which indicated virtually all metal had been adsorbed on to support.

The SEA method applied to $\mathrm{TiO}_{2}$ support did not result in high adsorption of the $\mathrm{Pt}$ precursor on $\mathrm{TiO}_{2}$. Therefore, $\mathrm{Pt} / \mathrm{TiO}_{2}$ was prepared using chloroplatinic acid by the incipient 
wetness method. A calculated volume of aqueous solution containing the Pt precursor was added dropwise to $\mathrm{TiO}_{2}$ to saturate the pore volume of the catalyst, which was subsequently dried at 383K overnight. The IWI and SEA catalysts were calcined in flowing air at temperatures from $573 \mathrm{~K}$ to $773 \mathrm{~K}$ at $1 \mathrm{~K} / \mathrm{min}$ to the final temperature and held for $3 \mathrm{~h}$. Following calcination, all catalysts were reduced under flowing $\mathrm{H}_{2}$ (Praxair, 99.999\%) at $523 \mathrm{~K}$ at $5 \mathrm{~K} / \mathrm{min}$ and holding for $2 \mathrm{~h}$.

\subsection{Catalyst Characterization}

Metal dispersion and active site density were measured by $\mathrm{CO}$ chemisorption at $313 \mathrm{~K}$ on a Micrometrics AutoChem 2020 Pulse Chemisorption System, assuming CO atom to surface metal atom stoichiometry of 1.0 for Pt and 2.0 for Pd based catalysts. Prior to CO exposure, the catalyst was pretreated in flowing $\mathrm{H}_{2}(10 \%$ in $\mathrm{He})$ at $50 \mathrm{~mL} / \mathrm{min}$ for $1 \mathrm{~h}$ at $523 \mathrm{~K}$. An average particle diameter was determined for all supported metals based on the measured dispersion of the metal.

\subsection{Catalytic Hydrogenation}

Batch hydrogenation of DMF and 2-hexanone was conducted in a HEL ChemScan highpressure parallel reaction system equipped with eight $16 \mathrm{~mL}$, independently controlled Hastelloy autoclave reactors. Reactors were loaded with a solution containing solid catalyst, substrate, nonane solvent, and dodecane as an internal standard. The reactors were operated at a pressures of $0.41 \mathrm{MPa}$ to $0.69 \mathrm{MPa} \mathrm{H}_{2}$ and temperatures ranging from $333 \mathrm{~K}$ to $393 \mathrm{~K}$. Standard reaction conditions were $0.55 \mathrm{MPa} \mathrm{H}_{2}, 353 \mathrm{~K}, 1.12 \mathrm{M}$ of substrate in nonane, metal catalyst $(0.2 \mathrm{~mol} \%$ of substrate loaded, $40 \mathrm{mg}$ ) for a total volume of $4.66 \mathrm{~mL}$. Prior to the addition of hydrogen, the reactors were purged with $\mathrm{N}_{2}$ three times and heated to reaction temperature. No conversion of the substrate was observed until the introduction of the reactive gas, $\mathrm{H}_{2}$. Experimental data for 
initial rate studies and for time course studies were obtained by running individual reactors for a desired reaction time. After each reaction, the reactor was immersed in an ice bath and quickly cooled to room temperature, after which the reactor was vented and purged with inert gas. The catalyst was then separated from the reaction mixture by centrifugation and filtration, and the filtered liquid was then diluted with acetone to reach a concentration suitable for quantification by GC/MS. Carbon balances for all experimental measurements were greater than $96 \%$.

\subsection{Product Analysis}

Quantitative analysis of products was performed using a Varian CP-3800 gas chromatograph (GC) equipped with a flame ionization detector (FID) coupled to a Varian 320MS mass spectrometer. Product compounds were separated using a FactorFour capillary column (VF-5 ms, $30 \mathrm{~m}$ length, $0.25 \mathrm{~mm}$ diameter) coated with a $0.25 \mathrm{~mm}$ thick stationary phase (5\% phenyl and 95\% dimethylpolysiloxane) with hydrogen as a carrier gas. Dodecane was present in all samples as an internal standard to normalize variability in sample size delivery and detector signal strength. Initial rates of DMF and 2-hexanone disappearance were evaluated using the slope of the linear portion of the conversion profile, for conversions $<25 \%$. Reactant conversion and product selectivity were defined as follows:

$$
\begin{gathered}
\text { Conversion }(\mathrm{mol} \%)=\frac{\text { moles of DMF or } 2 \text {-hexanone reacted }}{\text { moles of initial substrate }} \times 100 \% \\
\text { Selectivity }_{\text {species i }}(\mathrm{mol} \%)=\frac{\text { moles of species i }}{\sum \text { moles of product }} \times 100 \%
\end{gathered}
$$

Since the number of active metal centers per mass loading of all catalysts was determined by CO chemisorption, the turnover frequency (TOF) was calculated as:

$$
\mathrm{TOF}=\frac{\text { Moles of substrate reacted }}{(\text { Moles of active centers })(\text { seconds })}
$$




\section{Results}

\subsection{Hydrogenation of DMF over carbon-supported noble metals}

Prior to measuring the initial rates of DMF hydrogenation in the liquid phase, a number of systematic studies were performed to verify that neither external nor internal mass transfer affected the measured rates of reaction (see Supplementary Information, S1). After verification, all subsequent experiments were carried out using the appropriate stirring speed and catalyst particle size required to avoid effects of mass transfer.

The products of DMF hydrogenation over the supported noble metals reported in Table 1 include 2,5-dimethyltetrahydrofuran (DMTHF), 2-hexanone, 2-hexanol, and trace amounts of $n$ hexane. The turnover frequency (TOF) for each catalyst in Table 2 was determined on the basis of the initial rate of DMF consumption normalized by the number of active centers on the supported metal catalysts (quantified by CO chemisorption). The initial rate of DMF consumption measured at $353 \mathrm{~K}$ and $0.55 \mathrm{MPa}$ of $\mathrm{H}_{2}$, decreased in the order $\mathrm{Pt} / \mathrm{C}>\mathrm{Rh} / \mathrm{C}>\mathrm{Pd} / \mathrm{C}$ $>\mathrm{Ru} / \mathrm{C}$. Of these transition metals, only Pt/C exhibited high selectivity to products obtained by C-O bond hydrogenolysis (principally 2-hexanone and 2-hexanol), whereas all of the other catalysts exhibited lower activity and high selectivity for ring saturation to form DMTHF. The difference in activity and selectivity among the noble metals is due to the nature of the metal since all catalysts had comparable metal particle size (Table 1). Under the mild reaction conditions ( $353 \mathrm{~K}$ and $0.55 \mathrm{MPa}$ of $\mathrm{H}_{2}$ ) employed during liquid-phase hydrogenation, the main products observed for Pt and Pd catalysts are similar to those reported for gas-phase hydrogenation discussed earlier [6-8].

Since 2-hexanone and 2-hexanol are useful starting materials for C-C coupling chemistry [9], further experiments were undertaken with Pt/C in order to gain insight into the pathways for 
the formation of all products. Fig. 1 shows that for reaction times below 12 min., the concentrations of DMTHF, 2-hexanone, and 2-hexanol all increase linearly. For longer reaction times, the concentrations of these products increase with time in a sub-linear manner, coincident with a decrease in the rate of DMF consumption. These patterns suggest that the hydrogenation of DMF to DMTHF and the formation of 2-hexanone and 2-hexanol occur via parallel and independent pathways, and that the conversion of DMTHF to 2-hexanol is not a prominent pathway. This conclusion is verified by our experiments in which DMTHF was reacted over Pt/C under conditions identical to those used for hydrogenation of DMF. Only trace amounts of ringopened products, 2-hexanone and 2-hexanol ( $<5 \%$ yield), were observed even after extended reaction times $(2 \mathrm{~h})$. Therefore, despite previous studies proposing the contrary $[13,16]$, we conclude that DMTHF is not an intermediate to $\mathrm{C}-\mathrm{O}$ hydrogenolysis products under the conditions of the present study.

Another feature of DMF hydrogenation is the relationship of the concentrations of 2hexanol (HXL) to 2-hexanone (HEX) and 2-hexanol to DMTHF. Fig. 2 illustrates the variation in the concentrations of 2-hexanol to 2-hexanone as a function of the consumption of DMF. Below a DMF conversion of $\sim 50 \%$, the ratio of 2-hexanol to 2-hexanone is constant and increases only for DMF conversions above 50\%. The constancy of the ratio of HXL/HEX concentrations at low DMF conversions suggests that these species originate from a common intermediate, and not through secondary hydrogenation of 2-hexanone as suggested previously $[16,25]$. However, the increase in the ratio of HXL/HEX concentrations at higher conversions of DMF can be attributed to progressive hydrogenation of 2-hexanone, since 2-hexanone is now available in the system at significant concentrations. It is also evident from Fig. 1 that the ratio of concentrations of 2-hexanol to DMTMF is close to unity throughout the reaction. This behavior 
suggests the production of 2-hexanol occurs at a rate comparable to that for the production of DMTHF. Parallel formation of the three products, DMTHF, 2-hexanone, and 2-hexanol is also observed in Fig. S2, in which their selectivity remains constant during DMF conversions below $40 \%$.

Table 3 compares the measured initial rates of DMF consumption $\left(r_{D M F}\right)$, ring opening $\left(r_{R O}\right)$ and ring saturation $\left(r_{R S}\right)$ over $\mathrm{Pt} / \mathrm{C}$ at $0.55 \mathrm{MPa} \mathrm{H}_{2}, 353 \mathrm{~K}$. Also listed is the rate of 2-hexanol production $\left(r_{H X L}\right)$ from $\mathrm{DMF}$ and the rate of $\mathrm{C}=\mathrm{O}$ hydrogenation when 2-hexanone is reacted as the substrate $\left(r_{H E X}\right)$. It is noted that $r_{R O}$ is significantly larger than all other rates in the network, suggesting that cleavage of the aromatic $\mathrm{C}-\mathrm{O}$ bond of DMF to form ring opened products occurs more rapidly than both the hydrogenation of aromatic $\mathrm{C}=\mathrm{C}$ bonds to form DMTHF and the hydrogenation of the $\mathrm{C}=\mathrm{O}$ bond of 2-hexanone to form 2-hexanol.

\subsection{Effect of reactant concentration on the kinetics of DMF hydrogenation}

Experiments were conducted with initial DMF concentrations ranging from $0.66 \mathrm{M}$ to 1.23 M at $353 \mathrm{~K}, 0.55 \mathrm{MPa}$ (Fig. 3). The initial loading of DMF had minimal effect on both the rate of DMF consumption and the product selectivities. A similar dependence on substrate concentration has also been reported previously for the liquid-phase hydrogenation of DMF and 2-methylfuran over platinum oxide [21].

Experiments to determine the effect of hydrogen partial pressure on the kinetics of DMF hydrogenation were conducted by measuring initial rates of $r_{D M F}, r_{R O}$, and $r_{R S}$ for $\mathrm{H}_{2}$ pressures between $0.41 \mathrm{MPa}$ and $0.69 \mathrm{MPa}$. The rates of ring saturation and ring opening of DMF increased with increasing $\mathrm{H}_{2}$ partial pressure. The empirical rate orders on $\mathrm{H}_{2}$ partial pressure were determined from the slopes when reaction rates vs. $\mathrm{p}_{\mathrm{H} 2}$ are plotted on a natural log plot, as presented in Fig. 4. The slopes are $\sim 2$ for ring saturation and $\sim 0.6$ for ring opening, suggesting 
separate reaction mechanisms and rate-limiting steps for the two pathways - the addition of the fourth hydrogen atom for the path leading to ring saturation and the addition of the first hydrogen atom for the path leading to ring opening [26]. The lower order dependence on $\mathrm{p}_{\mathrm{H} 2}$ in $r_{R O}$ is reflected in the higher selectivity for 2-hexanone and 2-hexanol products obtained at lower $\mathrm{pH}_{\mathrm{H}}$.

\subsection{2-Hexanone hydrogenation over Pt/C}

2-hexanone formed by ring-opening hydrogenation of DMF can undergo further hydrogenation to produce 2-hexanol. The kinetics of this process were investigated by carrying out the hydrogenation of 2-hexanone over $5 \% \mathrm{Pt} / \mathrm{C}$ under conditions identical to those used for hydrogenation of DMF. The only product observed was 2-hexanol. The rate of 2-hexanone hydrogenation was similarly zero order in 2-hexanone and $\sim 1.2$ order in the partial pressure of $\mathrm{H}_{2}$ (Fig. 5). A similar dependence on the partial pressure of $\mathrm{H}_{2}$ has been reported by Sen and Vannice for the hydrogenation of acetone over various oxide-supported Pt catalysts resulting from the $2^{\text {nd }}$ addition of $\mathrm{H}$ atom being the rate determining step [27].

\subsection{Effects of reaction temperature}

Initial rates of all reaction pathways and selectivity were investigated for a temperature range of $343 \mathrm{~K}-373 \mathrm{~K}$. In general, an increase in temperature favors ring cleavage over ring saturation of DMF and increases the selectivity toward 2-hexanone over 2-hexanol, which is also shown in Fig. 2. The apparent activation energies, $\mathrm{E}_{\mathrm{app}}$, for all pathways were determined from Arrhenius plots of the initial rates of formation of DMTHF and initial rates of formation of ringopened products, 2-hexanone and 2-hexanol, during hydrogenation of DMF (Fig. 6). These values, along with the rate order dependence on reactants for each pathway, are listed in Table 4. The apparent activation energy for ring saturation of DMF to form DMTHF is $10.2 \mathrm{~kJ} / \mathrm{mol}$. By contrast, the apparent activation for ring-opening of DMF to form 2-hexanone and 2-hexanol is 
$45.3 \mathrm{~kJ} / \mathrm{mol}$. An Arrhenius plot for the hydrogenation of 2-hexanone to 2-hexanol is also shown in Fig. 6. The apparent activation energy for this process is $27.6 \mathrm{~kJ} / \mathrm{mol}$.

\subsection{Effects of catalyst support composition on the hydrogenation of DMF and 2-hexanone}

The effects of support composition on the hydrogenation of DMF and of 2-hexanone were investigated and the results are presented in Table 5. To isolate the effects of support composition, the Pt loading and particle size were kept constant, with the exception of $\mathrm{Pt} / \mathrm{TiO}_{2}$ for which the particle size was could not be controlled via the IWI method of Pt dispersion (Table 1).

The initial rates of DMF conversion and product distribution observed at $10 \% \mathrm{DMF}$ conversion remained unchanged independent of support composition (see Table 5). For all catalysts, the combined selectivity to 2-hexanone and 2-hexanol remained in the range of 90$95 \%$, and only trace amounts of hexane were observed due to the presence of acidic sites on the supports. Although support effects were not observed for DMF hydrogenation, they were observed for 2-hexanone hydrogenation to 2-hexanol. For all oxide-supported Pt catalysts, the rates of ketone hydrogenation are 2- to 5-fold higher than that for $\mathrm{Pt} / \mathrm{C}$. The enhancement in $\mathrm{C}=\mathrm{O}$ hydrogenation by oxide-supported Pt has been observed previously and is attributed to the Lewis acidity of the supports $[28,29]$. The free electrons of the oxygen atom in the carbonyl group of the ketone can coordinate to Lewis sites on the oxide support [28]. For the supports studied, the strength of the Lewis acid centers increases in the order of $\mathrm{Al}_{2} \mathrm{O}_{3}<\mathrm{TiO}_{2}<\mathrm{NbOPO}_{4}$. This trend is also reflected in the TOFs for the rate of 2-hexanone hydrogenation (Table 5). 


\section{Discussion}

\subsection{Mechanism of DMF hydrogenation}

The results of this study suggest that during hydrogenation of DMF, ring saturation to form DMTHF and ring opening to form 2-hexanone and 2-hexanol occur as parallel pathways rather than in series, as proposed previously $[13,16]$. The argument for sequential hydrogenation of the aromatic furan ring and subsequent ring opening of the tetrahydrofuran derivative is based on the weaker strength (by $\sim 28 \mathrm{~kJ} / \mathrm{mol}$ ) of the C-O bond in DMTHF than in DMF [30]. Our studies, however, demonstrate that $\mathrm{C}-\mathrm{O}$ bond cleavage occurs directly from the aromatic furan ring and does not occur with the saturated tetrahydrofuran ring. This behavior was also observed for hydrogenation of 2-methylfuran versus 2-methyltetrahydrofuran over $\mathrm{Pt} / \mathrm{C}$ in liquid phase flow systems [22]. This behavior suggests that the interaction between the aromatic ring and the metal surface plays a crucial role in weakening the aromatic $\mathrm{C}-\mathrm{O}$ bond, thereby enabling its cleavage. Several pieces of evidence support this view. For example, DFT studies find the binding strength of tetrahydrofuran with Pd surfaces to be weaker than that of furan [31]. Sum frequency generation vibration spectroscopy (SFG-VS) studies have shown that DMF adsorbs parallel to the surface of Pt via interaction with the $\pi$ orbitals of the aromatic ring, whereas DMTHF adsorbs upright via the $\mathrm{O}$ atom [12]. This configuration of DMF is further supported by theoretical studies, which demonstrate that DMF adsorption parallel, rather than perpendicular, to the surface of Pt provides higher stability [32].

The selectivity to ring opening versus ring saturation during DMF hydrogenation depends on the identity of the noble metal, as seen in Table 2. The degree of ring opening of furfural over $\mathrm{Pd}, \mathrm{Cu}$ and $\mathrm{Ni}$ catalysts has been attributed to differences in the strength of interaction between the ring and the metal surface and the type of surface intermediate each metal is able to stabilize 
[11]. Further insights come from DFT calculations, which reveal that the orbitals of DMF involved in the adsorption of this molecule depend on the metal [32]. DMF is found to bind parallel to noble metal surfaces either through a single, $\pi \mathrm{C}=\mathrm{C}$ bond or through two $\sigma$ bonds with the two carbon atoms of the $\mathrm{C}=\mathrm{C}$ bond. The latter form of bonding is preferred for $\mathrm{Pt}$, whereas the $\pi$-bonded configuration is more favorable over $\mathrm{Pd}, \mathrm{Ru}$, and $\mathrm{Rh}$. Of the noble metals investigated in our study, only Pt was highly selective for direct ring opening of the furan whereas $\mathrm{Pd}, \mathrm{Ru}$, and $\mathrm{Rh}$ were selective for saturation of the furan ring. This observation suggests that $\pi$-bonding is conducive to ring saturation and that $\sigma$-bonding is conducive to ring opening, since $\sigma$-bonding would disrupt the aromaticity of the furan ring by forming an oxametallacycle species. The presence of possible oxametallacycle intermediates on the surface of Pt during furan hydrogenation has been proposed based on SFG-VS studies [13]. The configuration of DMF adsorbed on metal sites can also be influenced by the degree of hydrogen coverage [32], which can lead to significant effects on the selectivity between ring opening and furan hydrogenation due to energetic differences [31]. However, in our liquid-phase reaction system, the concentration of hydrogen is limited by its low solubility in nonane. For the narrow range of $\mathrm{p}_{2}$ studied $\left(\mathrm{p}_{\mathrm{H} 2}=0.41 \mathrm{MPa}-0.69 \mathrm{MPa}\right)$, the coverage of $\mathrm{H}$ is expected to be in the Henry's law regime, and consequently the effects $\mathrm{H}$ coverage on adsorption of DMF and other organic species is expected to be negligible.

Our results suggest that the formation of 2-hexanone and 2-hexanol from DMF occur in parallel through a common intermediate formed after ring cleavage, since 2-hexanol was detected immediately despite the low concentrations of 2-hexanone present at initial conversions of DMF and the selectivity for the two products in the reactor remains constant until $\sim 40 \%$ conversion of DMF (Fig. S2). For extended reaction times for which the concentration of 2- 
hexanone becomes significant and the concentration of DMF is low, additional 2-hexanol is produced via secondary hydrogenation of 2-hexanone. Scheme 1 captures these possibilities.

The formation of DMTHF is envisioned to begin with the syn-addition of hydrogen across the $\mathrm{C}=\mathrm{C}$ bond of DMF adsorbed parallel to the Pt surface to form a dihydro intermediate. These intermediates are unlikely to be involved in ring opening and instead have been observed to contribute exclusively to the formation tetrahydrofuran species during hydrogenation over $\mathrm{Pt}$ (> 90\% selectivity) [15, 17]. Moreover, DFT calculations by Wang et al. of furan hydrogenation over Pd show that dihydro or trihydro intermediates are unlikely to undergo ring-opening due to the high energy barriers associated with these processes [31]. We note that dihydro and trihydro intermediates were not detected in the course of the present study, suggesting that further hydrogenation of these intermediates to DMTHF is rapid.

Since our method of identification and quantification (GC/MS) allowed us to distinguish between cis and trans isomers of DMTHF via characteristic retention times, it is interesting to observe that the production of the cis isomers is heavily favored over the production of the trans isomers, and that greater than $90 \%$ of DMTHF exists as the cis isomer at $10 \%$ conversion of DMF (Table 2). The preference for the cis isomer can be rationalized by the hypothesis that immediately after the first addition of $\mathrm{H}_{2}$, the second $\mathrm{C}=\mathrm{C}$ bond is hydrogenated in a similar manner before the dihydrofuran species can desorb, flip over, and re-adsorb to produce the trans isomer through another syn-addition of $\mathrm{H}_{2}$ across the remaining $\mathrm{C}=\mathrm{C}$ bond. This hypothesis is supported by observations that the selectivity to $c i s$-DMTHF increases up to $>99 \%$ at $10 \%$ DMF conversion, under higher $\mathrm{H}_{2}$ partial pressures ( $0.61 \mathrm{MPa}$ ) or under higher reaction temperatures (363K). Under these reaction conditions, the rate at which hydrogenation of the second $\mathrm{C}=\mathrm{C}$ 
bond occurs is very high, making it more difficult for desorption and re-adsorption of 2,5dimethyldihydrofuran to occur rapidly enough to enable the formation of trans-DMTHF.

We propose that the first step in the ring-opening of DMF involves reductive cleavage of the aromatic $\mathrm{C}-\mathrm{O}$ bond to form an enol intermediate. This species is postulated to be the precursor to both 2-hexanol and 2-hexanone. The Gibbs free energy difference at $353 \mathrm{~K}$ between the gas phase enol and its keto analog, 2-hex-4-enone, was calculated using DFT to be -33 $\mathrm{kJ} / \mathrm{mol}$. The enol intermediate is therefore likely to rapidly convert at reaction conditions to its thermodynamically favored keto tautomer, which can then undergo additional hydrogenation at the remaining $\mathrm{C}=\mathrm{C}$ bond to form 2-hexanone. We also note that the double bond at the $\alpha$ carbon of the enol can undergo hydrogenation before tautomerization to the keto form, resulting in the formation of 2-hexanol as a primary product, rather than as a secondary product of 2-hexanone hydrogenation. The proposed mechanism is supported by the observation that the initial ratio of 2-hexanol to 2-hexanone concentrations at low DMF conversions decreases with increasing temperature (Fig. 2) because the keto tautomer is favored at increasing temperatures over the enol form. The preference for forming 2-hexanone versus 2-hexanol after ring-opening of DMF is governed by the relative rates of tautomerization of the enol $\left(r_{T}\right)$ and hydrogenation of the enol $\left(r_{1}\right)$. The existence of a primary pathway for forming 2-hexanol directly from DMF is supported by the results shown in Table 5 for DMF and 2-hexanone hydrogenation over Pt supported on different oxides. We note that the selectivity for 2-hexanol at $10 \%$ DMF conversion is the same regardless of the support used because the production of 2-hexanol in this regime results directly from ring opening of DMF. At DMF conversion above 40\%, additional 2-hexanol is formed by secondary hydrogenation of 2-hexanone, a process that is enhanced by the Lewis acidity of the support. 


\subsection{Kinetic modeling of the hydrogenation of DMF}

To develop a model for the kinetics of DMF hydrogenation, the reaction network proposed in Scheme 1 is represented as the sequence of elementary reactions shown in Scheme 2.

Scheme 2 is based on a Langmuir-Hinshelwood model with all surface reactions occurring stepwise between an adsorbed organic species and a dissociated hydrogen atom. The symbols $*$ and ${ }^{*}$ H represent vacant sites on the catalyst surface that can accommodate organic species and atomic hydrogen, respectively. $K_{i}$ is the adsorption equilibrium constant for organic species $i$. Partially hydrogenated intermediates adsorbed on the surface are depicted as $\mathrm{I}_{\mathrm{ix}}$. However, none of these intermediates nor any unsaturated species were detected as stable products and, hence, the steps involving these species were treated as quasi-equilibrated or the species were treated as reactive intermediates in the pseudo steady-state approximation in the derivation of rate expressions (see Supporting Information S3).

The elementary reactions are grouped into six categories of reactions in Scheme 2.

Reactions 1 and 2 represent the adsorption of DMF and dissociative adsorption of $\mathrm{H}_{2}$, respectively. Reaction 3 depicts the formation of the ring-saturated product, DMTHF, after four step-wise additions of hydrogen atoms $\left(H_{* H}\right)$. As the ring becomes more distorted with each addition of hydrogen, the intermediates lift up from the surface until DMTHF, which is bound perpendicular to the surface through its oxygen atom [31], is formed. Reaction 4 involves the ring opening of adsorbed DMF during the addition of the first hydrogen atom, and sequential hydrogenations to form 2-hexanol (HXL) as a primary product. Reaction 5 leads to the formation of 2-hexanone (HEX) after tautomerization of the enol species $\left(I_{4 b}^{*}\right)$ to the keto species $\left(I_{5 a}^{*}\right)$, in which the rate is given by $r_{T}$. Finally, Reaction 6 accounts for the hydrogenation of the carbonyl 
group of HEX to form HXL as a secondary product. The intermediates portrayed in the scheme were not detected during product analyses but are proposed on the basis of intermediates suggested by DFT calculations for furan hydrogenation over Pd [31].

An important feature of the proposed mechanism is that the adsorption of organic species and $\mathrm{H}_{2}$ occur non-competitively, and therefore adsorption sites for organic species and for atomic hydrogen are treated separately. This choice was motivated by the observation that mechanisms involving competitive adsorption of DMF and $\mathrm{H}_{2}$ on a single site did not lead to rate expressions consistent with the observed dependencies on $\mathrm{H}_{2}$ partial pressure for ring opening and ring saturation, $\sim 0.61$ and $\sim 2.0$, respectively, and with the observed zero order dependence on DMF concentration for all reactions. Specifically, if the adsorption of reactants were truly competitive, we would observe a decrease in the rate of hydrogenation with increased loading of DMF due to increasing competition with hydrogen for surface coverage. Non-competitive adsorption between the substrates and $\mathrm{H}_{2}$ can occur if the catalyst surface is saturated with organic species but interstitial sites between the adsorbed species are likely to remain accessible for the much smaller hydrogen atoms. The observed zero order dependence with respect to DMF or HEX loading indicates saturation of surface sites by substrate. This non-competitive behavior in kinetic models is supported by experimental data for several hydrogenation reactions of aromatic hydrocarbons for which the reaction order in benzene partial pressure was observed to be zero [26].

The mechanism proposed in Scheme 2 was used to derive rate expressions for the rates of ring saturation and ring opening as a function of the concentrations of $\mathrm{DMF}\left(\mathrm{C}_{\mathrm{DMF}}\right)$ and 2hexanone $\left(\mathrm{C}_{\mathrm{HEX}}\right)$, and the partial pressure of $\mathrm{H}_{2}\left(\mathrm{p}_{\mathrm{H} 2}\right)$ (see Supplementary Information $\mathrm{S} 3$ for details). Ring saturation of DMF to produce DMTHF occurs via a sequence of steps in which 
one $\mathrm{H}$ atom is added at each step (Reaction 3). In order to capture the roughly second order (2) dependence of the rate of formation of DMTHF on $\mathrm{H}_{2}$ partial pressure, we assume that the first three additions of $\mathrm{H}$ atoms are quasi-equilibrated and that the fourth and final addition of hydrogen is rate-limiting. Under these constraints, the rate of ring-saturation is given by the following expression:

$$
r_{R S}=\frac{k_{R S} K_{1} C_{D M F}\left(\sqrt{K_{2} H_{H 2} P_{H 2}}\right)^{4}}{\left(1+K_{1} C_{D M F}+K_{6} C_{H E X}\right)\left(1+\sqrt{K_{2} H_{H 2} p_{H 2}}\right)}
$$

In this expression, $k_{R S}$ is the reaction rate constant for ring saturation, $K_{1}$ and $K_{6}$ are adsorption equilibrium constants for DMF and HEX, respectively, $K_{2}$ is the equilibrium constant for dissociative adsorption of $\mathrm{H}_{2}$, and $\mathrm{H}_{\mathrm{H} 2}$ is the Henry's constant relating the concentration of dissolved $\mathrm{H}_{2}$ in the liquid phase to the partial pressure of $\mathrm{H}_{2}, \mathrm{p}_{\mathrm{H} 2}$. Determination of $\mathrm{H}_{\mathrm{H} 2}$ for our reaction system can be found in Section 3 of the Supplementary Information.

Both HEX and HXL are produced after ring cleavage of DMF. To capture the experimentally observed $\sim 0.6$ rate order dependence in $r_{R O}$ with respect to $\mathrm{H}_{2}$ partial pressure, we propose that the rate-limiting step for ring opening is the irreversible addition of the first $\mathrm{H}$ atom to adsorbed DMF (Reaction 4). Under this assumption, the rate of ring opening is then given by the following expression:

$$
r_{R O}=\frac{k_{R O} K_{1} C_{D M F} \sqrt{K_{2} H_{H 2} p_{H 2}}}{\left(1+K_{1} C_{D M F}+K_{6} C_{H E X}\right)\left(1+\sqrt{K_{2} H_{H 2} p_{H 2}}\right)}
$$

where $k_{R O}$ is the reaction rate constant associated with ring opening.

The set of differential equations describing the temporal evolution in the concentrations of ring-opened $(\mathrm{HEX}+\mathrm{HXL}), \mathrm{C}_{\mathrm{RO}}$, and ring-saturated (DMTHF), $\mathrm{C}_{\mathrm{RS}}$, products formed duringDMF hydrogenation in a well stirred, batch reactor can be written as

$$
\frac{V}{W} \frac{d C_{D M F}}{d t}=-r_{R O}-r_{R S}
$$




$$
\begin{aligned}
& \frac{V}{W} \frac{d C_{R S}}{d t}=r_{R S} \\
& \frac{V}{W} \frac{d C_{R O}}{d t}=r_{R O}
\end{aligned}
$$

with the following initial conditions:

$$
t=0 ; \quad C_{D M F}=C_{D M F}^{0} C_{R O}=0 C_{R S}=0
$$

In eqns. $3-5, \mathrm{~V}$ is the solution volume in the reactor and $\mathrm{W}$ is the weight of catalyst.

Values for the rate and equilibrium constants appearing in eqns. 1 and 2 were evaluated by solving the system of differential equations for an initial set of these parameters to determine concentrations of DMF, DMTHF, and HEX+HXL as functions of time and then comparing these values to those obtained experimentally. The objective function in a nonlinear, least-squares regression was then minimized by varying the rate and equilibrium constants in order to obtain the best-fit values of these constants. The ordinary differential equation solver, ODE15s, and the nonlinear optimization solver for the residual sum of squares, fmincon, provided in Matlab were used for parameter estimation. The parameters evaluated at different temperatures $(343-363 \mathrm{~K})$ were correlated using the Arrhenius equation to obtain respective activation energies and preexponential factors. The kinetic parameters of eqns. 1 and 2 obtained in this manner are summarized in Table 6. Fig. 7a illustrates the extent to which the model of DMF hydrogenation kinetics capture the competitive ring opening vs. ring saturation behavior at $353 \mathrm{~K}$.

The equilibrium constant for the adsorption of $\mathrm{HEX}, \mathrm{K}_{6}$, was determined by fitting a model of the rate of HEX hydrogenation to HXL over Pt/C (see Supplementary Information, S5). The sequence of elementary steps in this study is described by Reaction 6 in Scheme 2. For the reaction conditions studied $(0.55 \mathrm{Mpa}, 333 \mathrm{~K}-353 \mathrm{~K})$, HXL was the only product observed and no evidence for the dehydrogenation of HXL to HEX was observed. The rate expression 
developed to describe the conversion of HEX to HXL when 2-hexanone is used as the substrate is as follows:

$$
r_{3}=\frac{k_{3} K_{6} C_{H E X}\left(\sqrt{K_{2} H_{H 2} p_{H 2}}\right)^{2}}{\left(1+K_{6} C_{H E X}+K_{4} C_{H X L}\right)\left(1+\sqrt{K_{2} H_{H 2} p_{H 2}}\right)}
$$

Values of the rate and equilibrium constants associated with HEX hydrogenation, eq. 7, were obtained by the parameter estimation procedure described earlier. Values of these constants at $353 \mathrm{~K}$ and their associated parameters are presented in Table 7. Comparison between the experimental data and the fitted model is shown in Fig. 8 for HEX hydrogenation at 353 K. Fits to experimental data obtained at other temperatures and plots of the rate and equilibrium constants appearing in eqn. 7 can be found in Figs. S3 and S4. The calculated activation energy $(23.7 \mathrm{~kJ} / \mathrm{mol})$ is consistent with the apparent activation energy determined from initial rate studies of HEX hydrogenation over Pt/C (Table 4).

The model of the reaction kinetics developed above was expanded to distinguish between production of HEX and HXL after C-O hydrogenolysis. As discussed earlier, HXL can be produced as both a secondary product by hydrogenation of $\operatorname{HEX}\left(r_{3}\right)$, and a primary product by hydrogenation of the enol intermediate $\left(r_{1}\right)$ before tautomerization to the keto $\left(r_{T}\right)$. The enol $\left(I_{4 b}\right)$ is treated as a reactive intermediate formed by ring-opening $\left(r_{R O}\right)$ of DMF and is consumed by competing reactions $\left(r_{1}\right.$ and $\left.r_{T}\right)$. The species $I_{4 a}$ and $I_{4 c}$ were also treated as reactive species in the stepwise addition of $\mathrm{H}$ atoms to form HXL as a primary product. Because the initial ratio of HXL to HEX was found to depend on $\mathrm{p}_{\mathrm{H} 2}$, we assumed that the tautomerization step is not in equilibrium in our reaction system. We also note that $10 \%$ of ring-opened products appear as HXL during initial conversion of DMF despite the keto form being thermodynamically preferred over the enol form $(\Delta \mathrm{G}=-33 \mathrm{~kJ} / \mathrm{mol})$, which suggests that $r_{l}$ occurs fast enough to compete with $r_{T}$. It is assumed that tautomerization is irreversible and once the keto tautomer is formed, it goes 
exclusively to form HEX after hydrogenation of the unsaturated $\mathrm{C}=\mathrm{C}$ bond, $r_{2}$. Therefore, the rate of HEX produced from DMF is governed by the rate of tautomerization, $r_{T}$.

The rate of production of $\operatorname{HEX}\left(r_{T}\right)$ and the rate of production of $\operatorname{HXL}\left(r_{1}\right)$ after ring opening of DMF are dependent on the coverage of the reactive intermediate, ENOL species $\left(I_{4 b}\right)$, given by

$$
\theta_{I 4 b}=\frac{\frac{k_{T} k_{R O} K_{1} C_{D M F}\left(\sqrt{K_{2} H_{H 2} p_{H 2}}\right)}{\left(1+K_{1} C_{D M F}+K_{6} C_{H E X}\right)\left(1+\sqrt{K_{2} H_{H 2} p_{H 2}}\right)}}{k_{1}\left(\frac{\sqrt{K_{2} H_{H 2} p_{H 2}}}{1+\sqrt{K_{2} H_{H 2} p_{H 2}}}\right)+k_{T}}
$$

To described the main reactions occurring after cleavage of the aromatic ring in DMF, the following additional rate expressions are developed based on experimental observations, assuming the rate-limiting step for hydrogenation of $\mathrm{C}=\mathrm{O}$ bonds involves the addition of a second hydrogen atom.

$$
\begin{gathered}
r_{T}=\frac{\frac{k_{T} k_{R O} K_{1} C_{D M F}\left(\sqrt{K_{2} H_{H 2} p_{H 2}}\right)}{\left(1+K_{1} C_{D M F}+K_{6} C_{H E X}\right)\left(1+\sqrt{K_{2} H_{H 2} p_{H 2}}\right)}}{k_{1}\left(\frac{\sqrt{K_{2} H_{H 2} p_{H 2}}}{1+\sqrt{K_{2} H_{H 2} p_{H 2}}}\right)+k_{T}} \\
r_{1}=\frac{\frac{k_{1} k_{R O} K_{1} C_{D M F}\left(\sqrt{K_{2} H_{H 2} p_{H 2}}\right)^{2}}{\left(1+K_{1} C_{D M F}+K_{6} C_{H E X}\right)\left(1+\sqrt{K_{2} H_{H 2} p_{H 2}}\right)^{2}}}{k_{1}\left(\frac{\sqrt{K_{2} H_{H 2} p_{H 2}}}{1+\sqrt{K_{2} H_{H 2} p_{H 2}}}\right)+k_{T}} \\
r_{3}=\frac{k_{3} K_{6} C_{H E X}\left(\sqrt{K_{2} H_{H 2} p_{H 2}}\right)^{2}}{\left(1+K_{1} C_{D M F}+K_{6} C_{H E X}+K_{3} C_{D M T H F}+K_{4} C_{H X L}\right)\left(1+\sqrt{K_{2} H_{H 2} p_{H 2}}\right)}
\end{gathered}
$$

where $k_{T}, k_{1}$, and $k_{3}$ are the reaction rate constants associated with the rate of tautomerization of enol, hydrogenation of the unsaturated bond of enol, and hydrogenation of $\mathrm{C}=\mathrm{O}$ of $\mathrm{HEX}$, respectively. $\mathrm{K}_{3}$ is the equilibrium constant for adsorption of DMTHF. The value of $\mathrm{K}_{3}$ appears in the equation for $\mathrm{r}_{3}$, since product inhibition was observed when DMTHF $(0.2 \mathrm{M})$ was added with 2-hexanone as a substrate during initial rate experiments. The initial rate of HEX hydrogenation was $\sim 10 \%$ slower with the presence of additional DMTHF. This inhibition was 
not observed when DMTHF (0.2 M) was added during the initial-rate experiments for DMF hydrogenation over Pt/C. But overall, the inhibition by DMTHF on $\mathrm{r}_{3}$ is expected to be minimal since the maximum concentration of this product reached is $0.1 \mathrm{M}$ for DMF conversions $>80 \%$.

The differential equation describing the concentration of ring-opened products, $\mathrm{C}_{\mathrm{RO}}$, can be replaced by the following two differential expressions to describe the concentrations of 2hexanone and 2-hexanol, $\mathrm{C}_{\mathrm{HEX}}$ and $\mathrm{C}_{\mathrm{HXL}}$.

$$
\begin{aligned}
& \frac{V}{W} \frac{d C_{H E X}}{d t}=r_{T}-r_{3} \\
& \frac{V}{W} \frac{d C_{H X L}}{d t}=r_{1}+r_{3}
\end{aligned}
$$

Estimates of the rate parameters involved in $r_{T}, r_{1}$ and $r_{3}$ were obtained by the same procedure described earlier. Arrhenius plots of the estimated values of rate constants and equilibrium constants for the kinetic model obtained for temperatures $343 \mathrm{~K}-363 \mathrm{~K}$ are shown in Fig. S6. Values of these constants at $353 \mathrm{~K}$ and their associated activation barriers and pre-exponential factors are summarized in Table 6.

Fig. 7(a) compares the concentration profiles for DMF, DMTHF, and HEX+HXL as functions of time predicted by the model and those observed experimentally and Fig. 7(b) presents a similar comparison for the effects of reaction temperature on the variation in the concentration of DMF as a function of time. Additional temporal plots comparing the experimental data to the kinetic model at additional temperatures are found in Fig. S5. In all instances, the quality of the agreement between the predictions by the model and the experimental data is good. The model captures the steady, linear conversion of DMF for short reaction times and the competitive nature between ring opening and ring saturation for the substrate. 
In addition, the model describes the parallel formation of all three products as observed experimentally (Fig. 7c) during initial conversion of DMF $(t<15 \mathrm{~min})-1$. ring saturation to produce DMTHF ( $\left.\left.\mathrm{r}_{\mathrm{RS}}\right), 2\right)$, tautomerization of ENOL intermediate $\left(\mathrm{r}_{\mathrm{T}}\right)$ after ring opening to produce HEX, and 3. hydrogenation of ENOL intermediate $\left(\mathrm{r}_{1}\right)$ after ring opening to produce HXL. For extended reaction times and higher conversions of DMF (>75\%), the major pathway to HXL is no longer via hydrogenation of the ENOL $\left(\mathrm{r}_{1}\right)$ but instead, secondary hydrogenation of HEX present in the system $\left(\mathrm{r}_{3}\right)$.

The predicted rate constant associated with the secondary hydrogenation of HEX to $\mathrm{HXL}, \mathrm{k}_{3}$, obtained from our investigation of HEX hydrogenation is $2.5 \mathrm{x}$ larger (Table 7 ) than the value of $\mathrm{k}_{3}$ predicted from the simulation DMF hydrogenation (Table 6). However, this larger value of $\mathrm{k}_{3}$ appearing in $\mathrm{r}_{3}$ is still insufficient to account for all $\mathrm{HXL}$ observed during the initial conversion of DMF. If we first assume that HXL is produced exclusively through secondary hydrogenation $\left(\mathrm{r}_{3}\right)$ and use the value of $\mathrm{k}_{3}=0.15 \mathrm{~mol} / \mathrm{g}$-min as determined from our study of HEX hydrogenation, we are still unable to capture the immediate production of HXL during initial conversion of DMF. As seen in Fig. S7a, assumption of secondary hydrogenation alone inevitably under predicts the amount of HXL present at the beginning of the reaction since $r_{3}$ is dependent on the quantity of HEX available. Alternatively, if we neglect the secondary hydrogenation and assume HXL is solely produced through the hydrogenation of the ENOL intermediate, $\mathrm{r}_{1}$, we are unable to capture the continuous production of HXL after DMF has been consumed (Fig. S7b). The fitted rate constant associated with the primary formation of HXL, $\mathrm{k}_{1}$, is predicted to be several times larger than that associated with the secondary formation of HXL, $\mathrm{k}_{3}$ (Table 6-7). But both rates are dependent on other intermediates present in the reactor, resulting in $\mathrm{r}_{1}$ to produce HXL during the initial phase of DMF hydrogenation when the 
concentration of HEX is too low for $r_{3}$ to be a significant and $r_{3}$ to produce HXL via hydrogenation of HEX after DMF is depleted.

The activation energies predicted for the three reaction pathways - ring opening, ring saturation, 2-hexanone hydrogenation follows the order of $E_{R S}<E_{H E X}<E_{R O}$, consistent with the trend in apparent activation energies determined empirically from initial rate experiments (Table 4). The calculated activation energies for ring opening and ring saturation are $45.4 \mathrm{~kJ} / \mathrm{mol}$ and $10.1 \mathrm{~kJ} / \mathrm{mol}$, respectively, and are consistent with the observed apparent activation energies, $E_{a p p}$, obtained from an analysis of the initial rates during DMF hydrogenation (Table 4). Our results also agree with the limited information in the literature concerning the kinetics of ring-opening of alkylfurans during liquid-phase hydrogenation. In these studies the step with highest activation energy is typically associated with breaking the aromatic $\mathrm{C}-\mathrm{O}$ bond of the furanic species [33].

The selectivity between ring saturation and ring opening is dependent on the relative magnitudes of $r_{R S}$ and $r_{R O}$. While the activation energy for the former process is lower, it has a higher order dependence on the concentration of $\mathrm{H}_{2}$ available. Since the concentration of $\mathrm{H}_{2}$ in liquid phase is low under the reaction conditions employed, the overall rate of formation of DMTHF occurs more slowly than the rate of formation of ring opened products through C-O bond hydrogenolysis (Table 3). A similar argument can be made for the selectivity between formation of 2-hexanone and 2-hexanol following ring opening of DMF. Since these products are produced by competing reactions involving the enol intermediate, the formation of 2-hexanol over 2-hexanone is again governed by the relative rates of hydrogenation of the $\mathrm{C}=\mathrm{C}$ bond $\left(r_{1}\right)$ and the tautomerization of the enol $\left(r_{T}\right)$. The rate constants for tautomerization and enol hydrogenation are comparable at $353 \mathrm{~K}$ (see Table 6). The activation barrier for tautomerization 
step is higher and the rate is independent of the $\mathrm{p}_{\mathrm{H} 2}$, whereas the hydrogenation of the $\mathrm{C}=\mathrm{C}$ bond has a lower activation barrier and a $\sim 1.0$ order dependence on $\mathrm{p}_{\mathrm{H} 2}$. Under the reaction conditions employed, the magnitude of $r_{T}$ is greater than the magnitude of $r_{1}$, resulting in 2-hexanone as the major product during DMF hydrogenation over Pt/C. An understanding of the influence of reaction conditions on the kinetics of DMF hydrogenation can be used to help tune the process to produce 2-hexanone selectively during DMF hydrogenation. Operation at low $\mathrm{p}_{\mathrm{H} 2}$ and elevated temperatures will favor ring opening over ring saturation, favor tautomerization over enol hydrogenation, and minimize $\mathrm{C}=\mathrm{O}$ hydrogenation to improve selectivity toward 2-hexanone. Indeed we were able to achieve $92 \%$ selectivity of 2-hexanone at $100 \%$ conversion of DMF by applying appropriate reaction conditions (0.41MPa, 393K) (Fig. 9). This is the highest selectivity to 2-hexanone achieved in liquid-phase hydrogenation under mild conditions.

\section{Conclusions}

The liquid-phase hydrogenation of DMF was investigated over carbon-supported Pt, Pd, $\mathrm{Rh}$, and $\mathrm{Ru}$ with the aim of identifying catalysts that exhibit selectivity for ring opening as opposed to ring saturation. High selectivity toward ring-opening products, 2-hexanone and 2hexanol, were observed only for $\mathrm{Pt} / \mathrm{C}$, whereas $\mathrm{Pd} / \mathrm{C}$, $\mathrm{Rh} / \mathrm{C}$, and $\mathrm{Ru} / \mathrm{C}$ produced 2,5dimethyltetrahydrofuran preferentially via ring saturation. The kinetics of DMF hydrogenation over $\mathrm{Pt} / \mathrm{C}$ in the liquid phase were found to be zero order in $\mathrm{DMF}$ and positive order in the partial pressure of $\mathrm{H}_{2}$. Time-course studies demonstrated that 2-hexanone and 2-hexanol are produced in parallel, and further hydrogenation of 2-hexanone to 2-hexanol is slow. Our proposed mechanism for DMF hydrogenation explains the experimental behaviors observed. The key element of the mechanism is the formation of an enol intermediate that rapidly isomerizes to the thermodynamically preferred keto form. The reason why this reaction pathway occurs 
preferentially on Pt is attributed to the specifics of how DMF bind to this metal. A microkinetic model was developed on the basis of the proposed mechanism and successfully describes the observed kinetics very well. The microkinetic model was used to show that both primary and secondary production of 2-hexanol from DMF and from 2-hexanone, respectively, are needed in order to obtain temporal profiles of $\mathrm{C}_{\mathrm{HXL}}$ that agreed with experimental observations for the duration of DMF hydrogenation. The activation barrier for ring opening of DMF was found to have a higher activation energy and a lower dependence on рн2 $_{2}$ than ring saturation. This finding shows that ring opening is favored by operating at elevated temperatures and low рн2. Using this strategy, we were able to achieve $92 \%$ selectivity to 2-hexanone at full conversion of DMF.

\section{Acknowledgements}

This work was funded by the Energy Biosciences Institute. This material is also supported by the National Science Foundation Graduate Research Fellowship under Grant No. 1106400. The authors will also like to acknowledge the contributions of Rachel Licht and Edward Buehler for theory calculations and development of kinetic model, respectively.

\section{Appendix A. Supplementary data}

Supplementary data associated with this article can be found in the online version, at

\section{References}

[1] Y. Román-Leshkov, J.N. Chheda, J.A. Dumesic, Science, 312 (2006) 1933-1937.

[2] R.M. West, Z.Y. Liu, M. Peter, J.A. Dumesic, ChemSusChem, 1 (2008) 417-424.

[3] G.W. Huber, J.N. Chheda, C.J. Barrett, J.A. Dumesic, Science, 308 (2005) 1446-1450.

[4] D.M. Alonso, J.Q. Bond, J.C. Serrano-Ruiz, J.A. Dumesic, Green Chem., 12 (2010) 992-999.

[5] J.Q. Bond, D.M. Alonso, D. Wang, R.M. West, J.A. Dumesic, Science, 327 (2010) 11101114.

[6] A. Corma, O. de la Torre, M. Renz, Energy Environ. Sci., 5 (2012) 6328.

[7] G. Li, N. Li, Z. Wang, C. Li, A. Wang, X. Wang, Y. Cong, T. Zhang, ChemSusChem, 5 (2012). 
[8] M. Balakrishnan, E.R. Sacia, A.T. Bell, ChemSusChem, 7 (2014) 1078-1085.

[9] E.R. Sacia, M. Balakrishnan, M.H. Deaner, K.A. Goulas, F.D. Toste, A.T. Bell, ChemSusChem, 8 (2015) 1726-1736.

[10] P. Biswas, J.-H. Lin, J. Kang, V.V. Guliants, Appl. Catal., A, 475 (2014) 379-385.

[11] S. Sitthisa, D.E. Resasco, Catal. Lett., 141 (2011) 784-791.

[12] C. Aliaga, C.-K. Tsung, S. Alayoglu, K. Komvopoulos, P. Yang, G.A. Somorjai, J. Phys. Chem. C, 115 (2011) 8104-8109.

[13] C.J. Kliewer, C. Aliaga, M. Bieri, W. Huang, C.-K. Tsung, J.B. Wood, K. Komvopoulos, G.A. Somorjai, J. Am. Chem. Soc., 132 (2010) 13088-13095.

[14] C.L. Wilson, J. Am. Chem. Soc., 70 (1948) 1313-1315.

[15] I.F. Bel'skii, N.I. Shuikin, Russ. Chem. Rev., 32 (1963) 307.

[16] J. Kang, A. Vonderheide, V.V. Guliants, ChemSusChem, 8 (2015) 3044-3047.

[17] E. Furimsky, Appl. Catal., 6 (1983) 159-164.

[18] X.W. Zhong He, Catalysis for sustainable energy, (2012) 28-52.

[19] D.M. Alonso, J.Q. Bond, J.A. Dumesic, Green Chem., 12 (2010) 1493-1513.

[20] R.C. Runnebaum, T. Nimmanwudipong, J. Doan, D.E. Block, B.C. Gates, Catal. Lett., 142 (2012) 664-666.

[21] H.A. Smith, J.F. Fuzek, J. Am. Chem. Soc., 71 (1949) 415-419.

[22] J. Luo, M. Monai, H. Yun, L. Arroyo-Ramírez, C. Wang, C.B. Murray, P. Fornasiero, R.J. Gorte, Catal. Lett., 146 (2016) 711-717.

[23] A.V. Mironenko, M.J. Gilkey, P. Panagiotopoulou, G. Facas, D.G. Vlachos, B. Xu, J. Phys. Chem. C, 119 (2015) 6075-6085.

[24] J. Miller, J. Catal., 225 (2004) 203-212.

[25] H.-Y. Zheng, Y.-L. Zhu, B.-T. Teng, Z.-Q. Bai, C.-H. Zhang, H.-W. Xiang, Y.-W. Li, J.

Mol. Catal. A: Chem., 246 (2006) 18-23.

[26] S.D. Lin, M.A. Vannice, J. Catal., 143 (1993) 539-553.

[27] B. Sen, M.A. Vannice, J. Catal., 113 (1988) 52-71.

[28] Y. Román-Leshkov, M.E. Davis, ACS Catalysis, 1 (2011) 1566-1580.

[29] L.R. Baker, G. Kennedy, M. Van Spronsen, A. Hervier, X. Cai, S. Chen, L.W. Wang, G.A.

Somorjai, J. Am. Chem. Soc., 134 (2012) 14208-14216.

[30] F.L. Pilar, J.R. Morris, J. Chem. Phys., 34 (1961) 389-392.

[31] S. Wang, V. Vorotnikov, D.G. Vlachos, Green Chem., 16 (2014) 736-747.

[32] V. Vorotnikov, D.G. Vlachos, J. Phys. Chem. C, 119 (2015) 10417-10426.

[33] L. Faba, E. Díaz, S. Ordóñez, Appl. Catal., B, 160-161 (2014) 436-444. 
Tables

\begin{tabular}{cccc}
\hline & $\begin{array}{c}\text { Method of } \\
\text { Preparation }\end{array}$ & $\begin{array}{c}\text { M/Support } \\
\text { Density } \\
\left(\mathbf{m g ~ M} / \mathbf{m}^{2}\right. \\
\text { support) }\end{array}$ & $\begin{array}{c}\text { Dp, Particle } \\
\text { Size (nm) }\end{array}$ \\
\hline $5 \% \mathrm{Pt} / \mathrm{C}$ & As received & 0.074 & 4.6 \\
$10 \% \mathrm{Pd} / \mathrm{C}$ & As received & 0.148 & 5.4 \\
$5 \% \mathrm{Rh} / \mathrm{C}$ & As received & 0.074 & 4.5 \\
$5 \% \mathrm{Ru} / \mathrm{C}$ & As received & 0.074 & 5.3 \\
$1.1 \% \mathrm{Pt} / \mathrm{NBP}$ & SEA & 0.074 & 4.0 \\
$1.4 \% \mathrm{Pt} / \mathrm{Al} 2 \mathrm{O} 3$ & SEA & 0.074 & 4.7 \\
$1.4 \% \mathrm{Pt} / \mathrm{TiO} 2$ & IWI & 0.074 & 15.5 \\
\hline
\end{tabular}

Table 1: Density of supported metal and average particle size for metal nanoparticles. Average particle size determined by $\mathrm{CO}$ chemisorption. Commercial catalysts (carbon supports) were used as received. Other catalysts were either prepared by strong electrostatic adsorption (SEA) or by incipient witness impregnation (IWI) methods.

\begin{tabular}{cccccc}
\hline \multirow{2}{*}{$\begin{array}{c}\text { Hydrogenation } \\
\text { Catalyst }\end{array}$} & TOF $\left(\mathbf{s}^{-\mathbf{1}}\right)$ & $\begin{array}{c}\text { DMTHF } \\
\text { (\% cis) }\end{array}$ & 2-hexanone & 2-hexanol & $\begin{array}{c}\text { Total R.O. } \\
\text { products }\end{array}$ \\
\hline $5 \% \mathrm{Pt} / \mathrm{C}$ & 1.77 & $6.0(95)$ & 85 & 9.1 & 93.6 \\
$5 \% \mathrm{Rh} / \mathrm{C}$ & 0.62 & $95(91)$ & 4.6 & 0.0 & 4.6 \\
$10 \% \mathrm{Pd} / \mathrm{C}$ & 0.25 & $100(86)$ & 0.0 & 0.0 & 0.0 \\
$5 \% \mathrm{Ru} / \mathrm{C}^{\mathrm{b}}$ & 0.00 & -- & -- & -- & - \\
$5 \% \mathrm{Ru} / \mathrm{C}^{\mathrm{c}}$ & 0.27 & $69(90)$ & 27 & 3.1 & 25 \\
\hline
\end{tabular}

${ }^{a}$ Selectivity of the products observed at $10 \%$ conversion of DMF

${ }^{\mathrm{b}} \mathrm{Ru} / \mathrm{C}$ unreactive at $353 \mathrm{~K}$

${ }^{c}$ Performed at $\mathrm{T}=433 \mathrm{~K}$ since reactions below $433 \mathrm{~K}$ exhibited a significant induction phase Table 2: Turnover frequency (TOF) for DMF consumption and product selectivity for carbonsupported noble metals. TOFs normalized by the total number of surface metal atoms. $0.2 \mathrm{~mol} \%$ metal loading, $\mathrm{T}=353 \mathrm{~K}, \mathrm{p}_{\mathrm{H} 2}=0.55 \mathrm{MPa}, 1.12 \mathrm{M}$ DMF in nonane, $750 \mathrm{rpm}$.

\begin{tabular}{lc}
\hline & TOF $\left(\mathbf{s}^{\mathbf{1}}\right)$ \\
\hline rDMF & 1.75 \\
rRO & 1.63 \\
rRS & 0.12 \\
rHXL & 0.15 \\
rHEX & 0.67 \\
\hline
\end{tabular}

Table 3: TOFs obtained from initial rates for hydrogenation of DMF over $5 \% \mathrm{Pt} / \mathrm{C}, 0.2 \mathrm{~mol} \%$ $\mathrm{Pt} / \mathrm{C}, \mathrm{T}=353 \mathrm{~K}, \mathrm{p}_{\mathrm{H} 2}=0.55 \mathrm{MPa}, 1.12 \mathrm{M}$ DMF in nonane, $750 \mathrm{rpm}$. $\mathrm{r}_{\mathrm{HEX}}$, was determined using 2-hexanone as the reactant. 


\begin{tabular}{cccc}
\hline Rates of Reaction Network & $\boldsymbol{\beta}$ & $\boldsymbol{\gamma}$ & $\mathbf{E}_{\text {app }}(\mathbf{k J} / \mathbf{m o l})$ \\
\hline Ring opening: $\mathrm{r}_{\mathrm{RO}}$ & $\sim 0$ & 0.6 & 45.3 \\
Ring saturation: $\mathrm{r}_{\mathrm{RS}}$ & $\sim 0$ & 2 & 10.2 \\
2-Hexanone hydrogenation: $\mathrm{r}_{\mathrm{HEX}}$ & $\sim 0$ & 1.2 & 27.6 \\
\hline
\end{tabular}

Table 4: Apparent rate parameters for the hydrogenation of 2,5-dimethylfuran and 2-hexanone on Pt. $\beta$ and $\gamma$ are values of rate-order dependence on the initial concentration of DMF and $\mathrm{p}_{\mathrm{H} 2 \text {, }}$ respectively. $\mathrm{E}_{\text {app }}$ calculated over the temperature range of $333-363 \mathrm{~K}$ and for a $\mathrm{H}_{2}$ partial pressure of $0.55 \mathrm{MPa}$ based on the Arrhenius relation: rate $\alpha \exp \left(-\frac{E_{a p p}}{R T}\right) C_{D M F}^{\beta} C_{H 2}^{\gamma}$. The concentration of $\mathrm{H}_{2}$ in the system was calculated from the $\mathrm{p}_{\mathrm{H} 2}$ and the Henry's coefficient at the reaction conditions (see Supplementary Information, S2).

\begin{tabular}{|c|c|c|c|c|c|c|}
\hline \multirow[b]{2}{*}{ Supported Pt Catalyst } & \multicolumn{2}{|c|}{$\operatorname{TOF}\left(s^{-1}\right)$} & \multicolumn{4}{|c|}{$\%$ Selectivity ${ }^{a}$} \\
\hline & rDMF & rHEX & DMTHF & $\begin{array}{c}2- \\
\text { hexanon } \\
\text { e }\end{array}$ & $\begin{array}{c}\text { 2- } \\
\text { hexanol }\end{array}$ & n-hexane \\
\hline $5 \% \mathrm{Pt} / \mathrm{C}$ & 1.8 & 0.7 & 6.0 & 85.0 & 9.1 & 0.0 \\
\hline $1.1 \% \mathrm{Pt} / \mathrm{NBP}$ & 2.0 & 3.2 & 8.0 & 81.8 & 8.8 & 1.3 \\
\hline $1.4 \% \mathrm{Pt} / \mathrm{A} 12 \mathrm{O} 3$ & 2.0 & 1.8 & 7.1 & 82.8 & 9.4 & 0.7 \\
\hline $1.4 \% \mathrm{Pt} / \mathrm{TiO} 2$ & 1.7 & 2.3 & 10.2 & 74.2 & 11.2 & 4.5 \\
\hline
\end{tabular}

a Selectivity of the products observed at $10 \%$ conversion of DMF

Table 5: Turnover frequencies (TOFs) for hydrogenation over supported Pt catalysts when DMF or 2-hexanone was used as the substrate. TOFs normalized by the total number of surface metal atoms. $0.2 \mathrm{~mol} \%$ metal loading, $\mathrm{T}=353 \mathrm{~K}, \mathrm{p}_{\mathrm{H} 2}=0.55 \mathrm{MPa}, 1.12 \mathrm{M}$ substrate in nonane, 750 rpm.

\begin{tabular}{|c|c|c|c|c|c|}
\hline \multirow{2}{*}{$\begin{array}{c}\begin{array}{c}\text { Rate or Equilibrium } \\
\text { Constant }\end{array} \\
\mathrm{k}_{\mathrm{RS}}\end{array}$} & \multicolumn{2}{|c|}{ Parameters at 353K } & \multicolumn{2}{|c|}{$\mathrm{E}_{\mathbf{a}}$ or $\Delta \mathbf{H}_{\mathbf{a d}}$} & \multirow{2}{*}{$\begin{array}{c}\ln (\mathbf{A}) \text { or } \\
\mathbf{S}_{\mathbf{a d}} \\
5.2\end{array}$} \\
\hline & 5.7 & $\mathrm{~mol} / \mathrm{g}-\mathrm{min}$ & 10.1 & $\mathrm{~kJ} / \mathrm{mol}$ & \\
\hline $\mathrm{k}_{\mathrm{RO}}$ & 0.09 & $\mathrm{~mol} / \mathrm{g}-\mathrm{min}$ & 45.4 & $\mathrm{~kJ} / \mathrm{mol}$ & 12.9 \\
\hline $\mathrm{k}_{\mathrm{T}}$ & 8.74 & $\mathrm{~mol} / \mathrm{g}-\mathrm{min}$ & 9.6 & $\mathrm{~kJ} / \mathrm{mol}$ & 5.4 \\
\hline $\mathrm{k}_{1}$ & 7.69 & $\mathrm{~mol} / \mathrm{g}-\mathrm{min}$ & 4.8 & $\mathrm{~kJ} / \mathrm{mol}$ & 3.6 \\
\hline $\mathrm{k}_{3}$ & 0.06 & $\mathrm{~mol} / \mathrm{g}-\mathrm{min}$ & 11.2 & $\mathrm{~kJ} / \mathrm{mol}$ & 1.0 \\
\hline $\mathrm{K}_{1}$ & 13 & $\mathrm{~L} / \mathrm{mol}$ & -12.3 & $\mathrm{~kJ} / \mathrm{mol}$ & -1.6 \\
\hline $\mathrm{K}_{2}$ & 0.56 & $\mathrm{~L} / \mathrm{mol}$ & -3.8 & $\mathrm{~kJ} / \mathrm{mol}$ & -1.9 \\
\hline $\mathrm{K}_{3}$ & 12 & $\mathrm{~L} / \mathrm{mol}$ & -7.8 & $\mathrm{~kJ} / \mathrm{mol}$ & -0.18 \\
\hline
\end{tabular}

Table 6: Rate parameters obtained by non-linear, least squares fitting of experimental data to proposed kinetic model for the reaction network of DMF hydrogenation (see text for details of fitting procedure). 


\begin{tabular}{|c|c|c|c|c|c|}
\hline \multirow{2}{*}{$\begin{array}{c}\begin{array}{c}\text { Rate or Equilibrium } \\
\text { Constant }\end{array} \\
\mathrm{k}_{3}\end{array}$} & \multicolumn{2}{|c|}{ Parameters at 353K } & \multicolumn{2}{|c|}{$\mathbf{E}_{\mathbf{a}}$ or $\Delta \mathbf{H}_{\mathrm{ad}}$} & \multirow{2}{*}{$\begin{array}{c}\ln (\mathbf{A}) \text { or } \\
\mathbf{S}_{\text {ad }} \\
6.2\end{array}$} \\
\hline & 0.15 & $\mathrm{~mol} / \mathrm{g}-\mathrm{min}$ & 23.7 & $\mathrm{~kJ} / \mathrm{mol}$ & \\
\hline $\mathrm{K}_{2}$ & 0.58 & L/mol & -4.8 & $\mathrm{~kJ} / \mathrm{mol}$ & -2.2 \\
\hline $\mathrm{K}_{6}$ & 15 & $\mathrm{~L} / \mathrm{mol}$ & -16.1 & $\mathrm{~kJ} / \mathrm{mol}$ & -2.8 \\
\hline $\mathrm{K}_{4}$ & 25 & $\mathrm{~L} / \mathrm{mol}$ & -12.0 & $\mathrm{~kJ} / \mathrm{mol}$ & -0.9 \\
\hline
\end{tabular}

Table 7: Rate parameters involved in eq. 7 obtained by non-linear, least squares fitting of experimental data for the hydrogenation of 2-hexanone to 2-hexanol. 


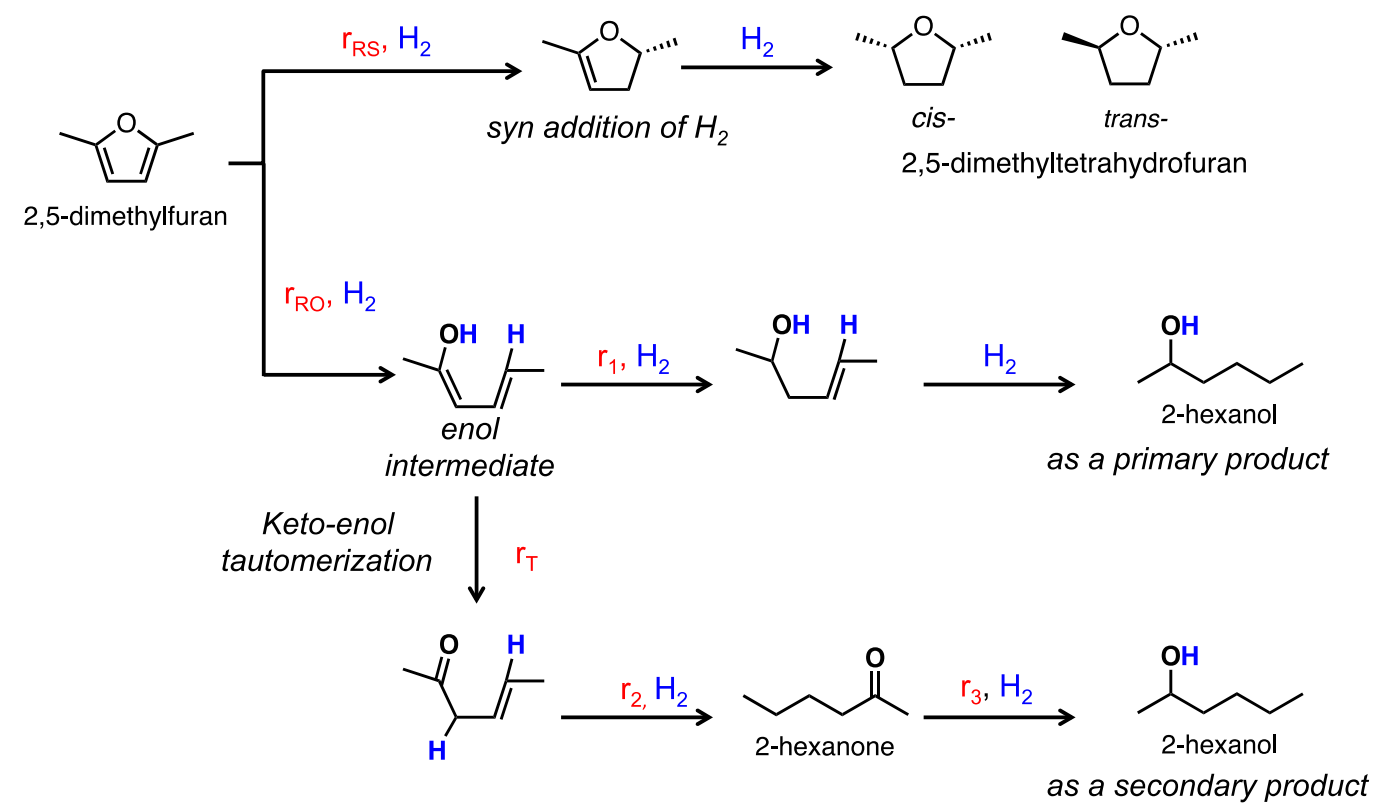

Scheme 1. Proposed reaction network for the hydrogenation of DMF into ring saturated and ring opened products over $\mathrm{Pt} / \mathrm{C}$. 


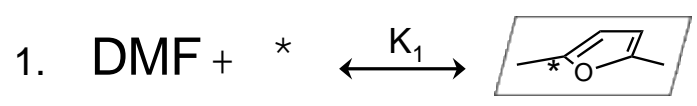

2. $\mathrm{H}_{2}+2 \quad \mathrm{H} \stackrel{\mathrm{K}_{2}}{\longleftrightarrow} \stackrel{\mathrm{H}_{H}^{\mathrm{H}}}{\mathrm{H}}$

\section{DMTHF +}

$\uparrow \mathrm{K}_{3}$

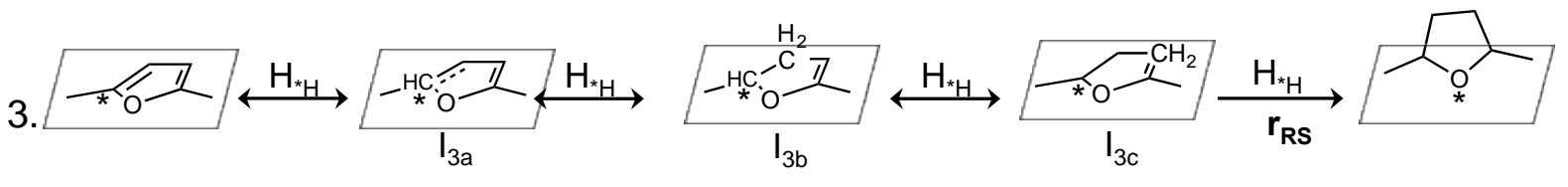

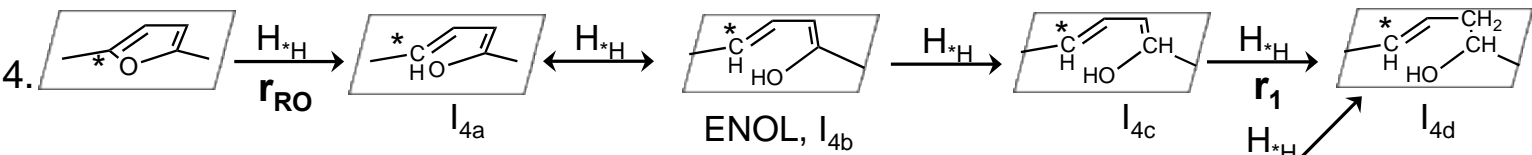

5.

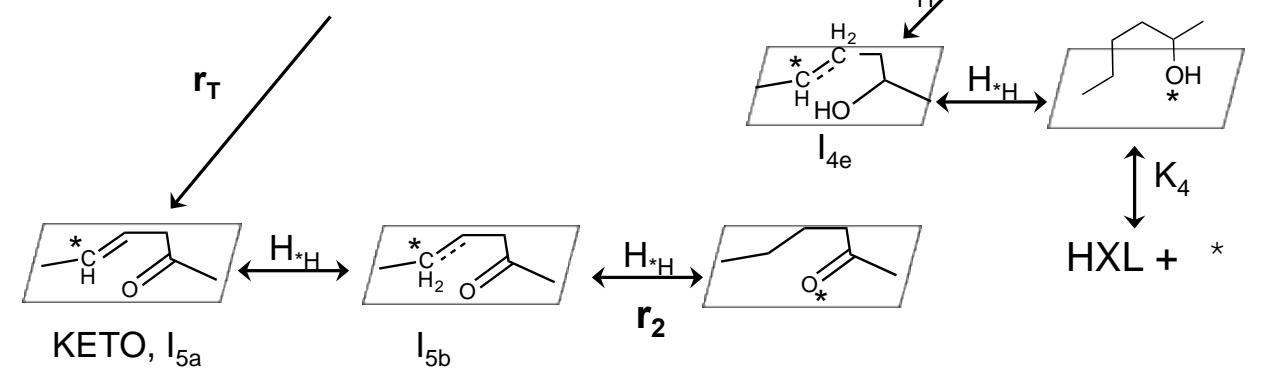

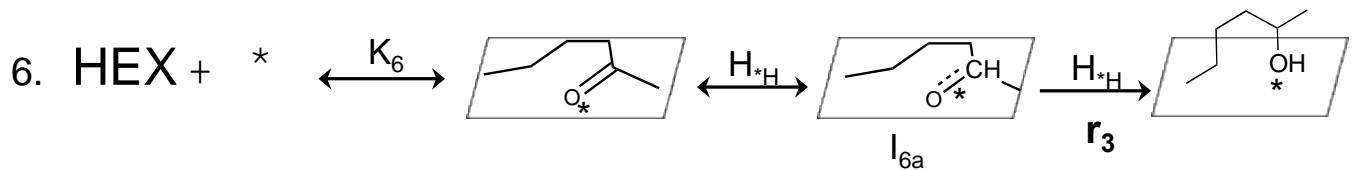

Scheme 2. Schematic of the elementary reactions involved in the overall reaction network shown in Scheme 1. 


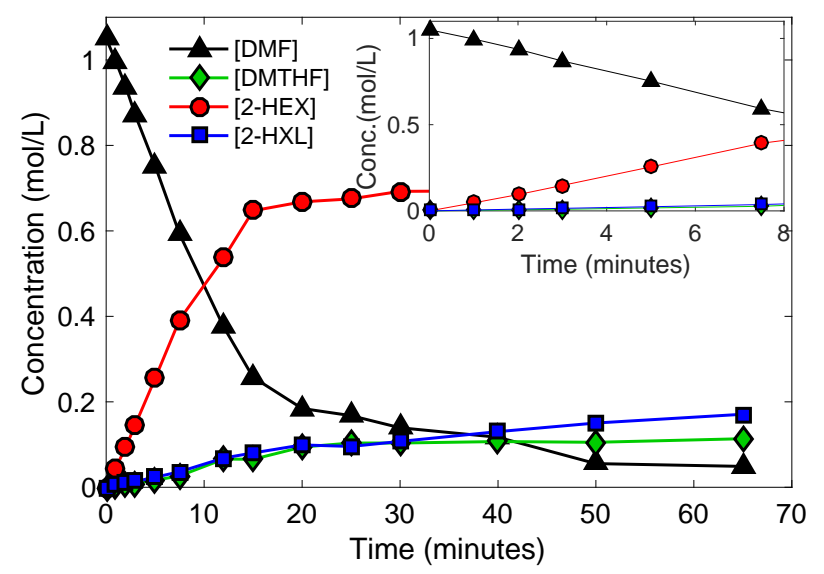

Fig. 1: Concentration profile of reactor composition during the course of DMF hydrogenation over 5\% Pt/C. $0.2 \mathrm{~mol} \% \mathrm{Pt} / \mathrm{C}, \mathrm{T}=353 \mathrm{~K}, \mathrm{p}_{\mathrm{H} 2}=0.55 \mathrm{MPa}, 1.04 \mathrm{M} \mathrm{DMF}$ in nonane, 750rpm.

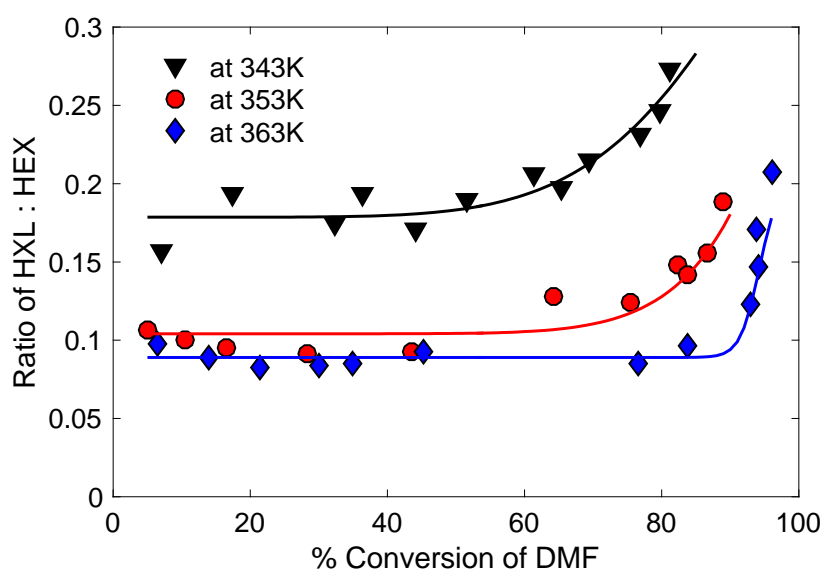

Fig. 2: Effect of temperature on the ratio of concentration of 2-hexanol to 2-hexanone (HXL:HEX) during the course of DMF conversion. $0.2 \mathrm{~mol} \%$ loading $\mathrm{Pt} / \mathrm{C}, \mathrm{p}_{\mathrm{H} 2}=0.55 \mathrm{MPa}$, $1.12 \mathrm{M}$ DMF in nonane, $750 \mathrm{rpm}, \mathrm{T}=343 \mathrm{~K}, 353 \mathrm{~K}, 363 \mathrm{~K}$. 


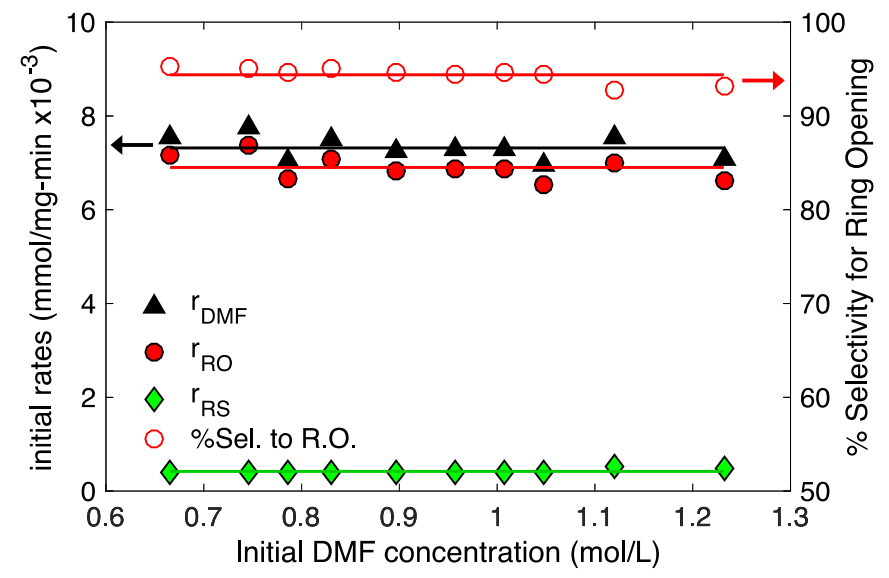

Fig. 3: Effect of initial DMF concentration on selectivity toward ring opening and on the initial rates of DMF consumption ( $\left.\mathrm{r}_{\mathrm{DMF}}\right)$, ring opening $\left(\mathrm{r}_{\mathrm{RO}}\right)$ and ring saturation $\left(\mathrm{r}_{\mathrm{RS}}\right)$ using 5\% Pt/C. 0.2 $\mathrm{mol} \% \mathrm{Pt} / \mathrm{C}, \mathrm{T}=353 \mathrm{~K}, \mathrm{p}_{\mathrm{H} 2}=0.55 \mathrm{MPa}, 0.66 \mathrm{M}-1.23 \mathrm{M}$ DMF in nonane, 750rpm.

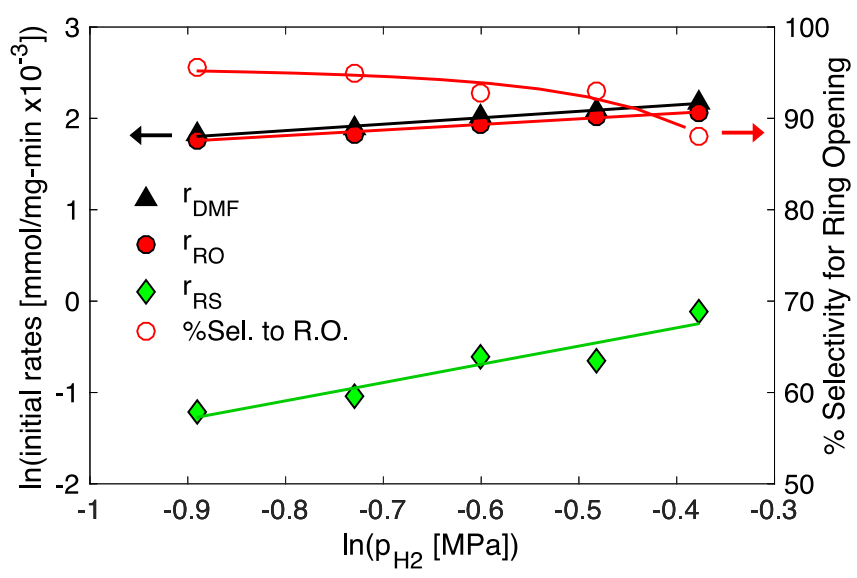

Fig. 4: Effect of $\mathrm{p}_{\mathrm{H} 2}$ on the selectivity to ring opening and on initial rates of DMF consumption $\left(\mathrm{r}_{\mathrm{DMF}}\right)$, ring opening $\left(\mathrm{r}_{\mathrm{RO}}\right)$, and ring saturation $\left(\mathrm{r}_{\mathrm{RS}}\right)$ using $5 \% \mathrm{Pt} / \mathrm{C} .0 .2 \mathrm{~mol} \%$ loading $\mathrm{Pt} / \mathrm{C}, \mathrm{T}=$ $353 \mathrm{~K}, \mathrm{p}_{\mathrm{H} 2}=0.41-0.69 \mathrm{MPa}, 1.12 \mathrm{M} \mathrm{DMF}$ in nonane, $750 \mathrm{rpm}$. 


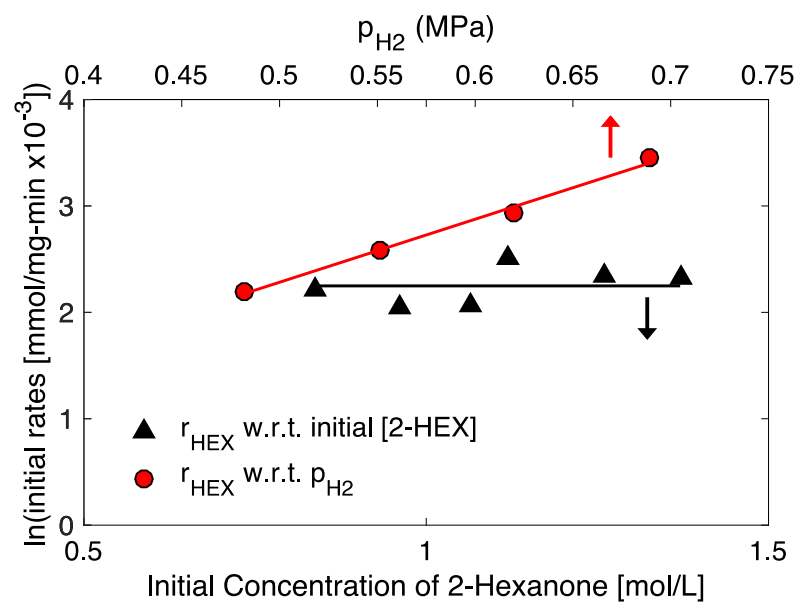

Fig. 5: Effect of initial 2-hexanone concentration and effect of $\mathrm{p}_{\mathrm{H} 2}$ on the initial rate of hydrogenation of 2-hexanone to 2-hexanol using 5\% Pt/C, $0.2 \mathrm{~mol} \% \mathrm{Pt} / \mathrm{C}, \mathrm{T}=353 \mathrm{~K}, \mathrm{p}_{2}=$ 0.48-0.69 MPa, 0.85-1.41 M DMF in nonane, $750 \mathrm{rpm}$.

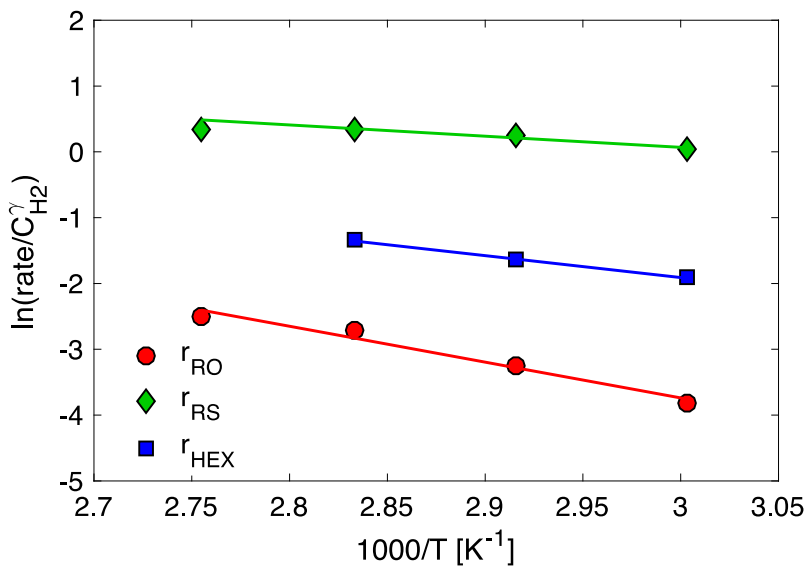

Fig. 6: Arrhenius plots of initial rates normalized by dependence on $\mathrm{C}_{\mathrm{H} 2}{ }^{\alpha}$ for reaction temperatures $\left(343-373 \mathrm{~K}\right.$ ) using 5\% Pt/C, $0.2 \mathrm{~mol} \%$ loading Pt/C, T $=343-373 \mathrm{~K}, \mathrm{p}_{\mathrm{H} 2}=0.55$ $\mathrm{MPa}, 1.12 \mathrm{M}$ DMF in nonane, $750 \mathrm{rpm}$. $\mathrm{r}_{\mathrm{HEX}}$ was determined using 2-hexanone as the reactant. 

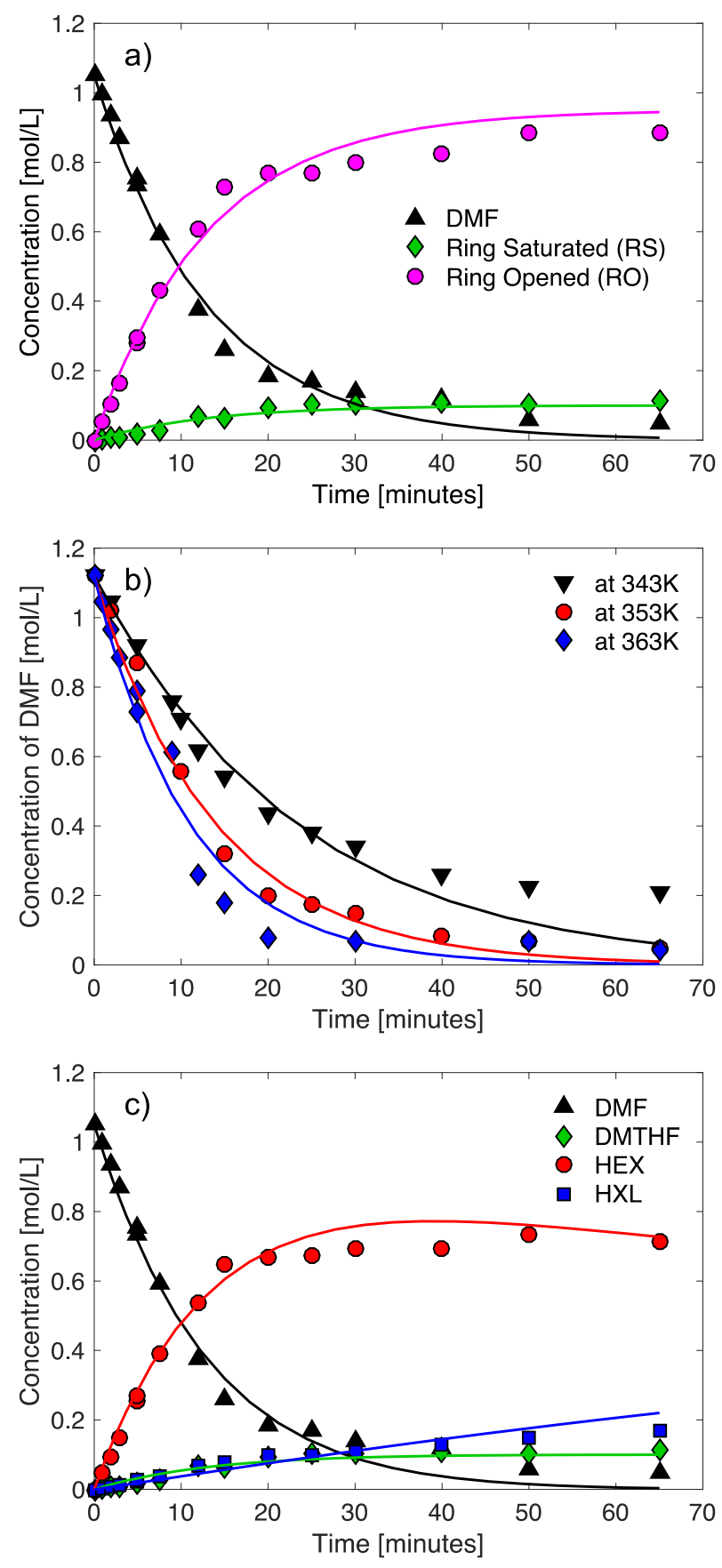

Fig. 7: Comparison of experimental data (symbols) and concentration profiles fitted for the model (lines) during DMF hydrogenation over $5 \% \mathrm{Pt} / \mathrm{C}$ for a) the parallel pathways of ring opening (HEX, HXL) and ring saturation (DMTHF) at $\mathrm{T}=353 \mathrm{~K}, 0.2 \mathrm{~mol} \% \mathrm{Pt} / \mathrm{C}, \mathrm{p}_{\mathrm{H} 2}=0.55$ $\mathrm{MPa}, 1.04 \mathrm{M}$ DMF in nonane, $750 \mathrm{rpm}$. b) DMF in the system at temperatures (343 K-363 K). c) all observed products of DMF at conditions in a). 


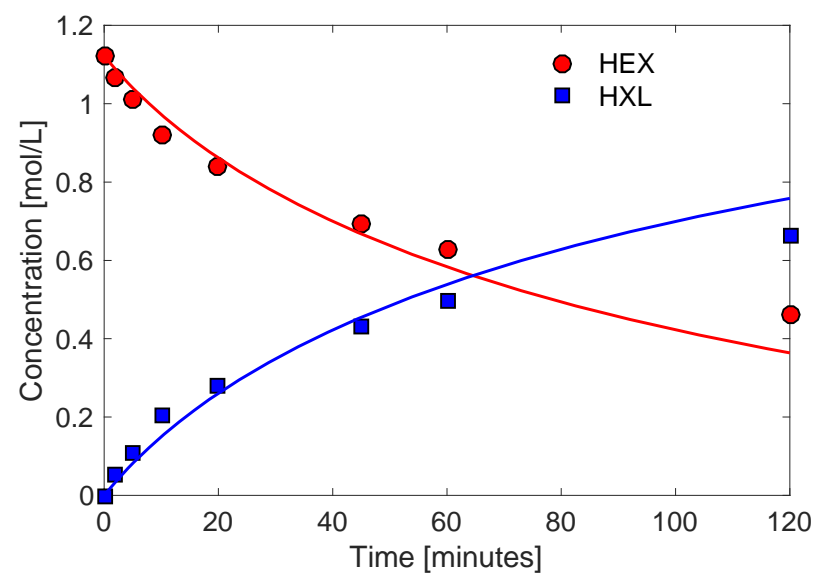

Fig. 8. Comparison of experimental and fitted concentration profiles for 2-hexanone hydrogenation to 2-hexanol over 5\% Pt/C 353K. Reactions performed using $0.2 \mathrm{~mol} \% \mathrm{Pt} / \mathrm{C}$, $\mathrm{p}_{\mathrm{H} 2}$ $=0.55 \mathrm{MPa}, 1.12 \mathrm{M}$ 2-hexanone in nonane, $750 \mathrm{rpm}$. Model fit: solid lines. Measurement: symbols.

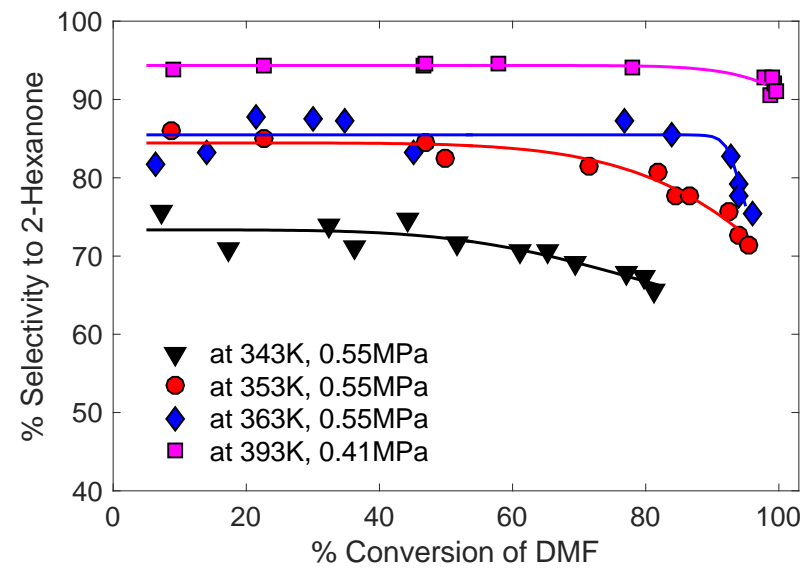

Fig. 9: Selectivity toward 2-hexanone as a function of DMF conversion and temperature. All hydrogenations performed at $0.2 \mathrm{~mol} \%$ active $5 \% \mathrm{Pt} / \mathrm{C}, \mathrm{T}=353 \mathrm{~K}, \mathrm{p}_{\mathrm{H} 2}=0.55 \mathrm{MPa}, 1.12 \mathrm{M}$ DMF in nonane, $750 \mathrm{rpm}$, except for the optimized reaction $(\mathrm{T}=493 \mathrm{~K}, 0.42 \mathrm{MPa})$ to improve selectivity toward 2-hexanone. Solid lines are present to guide the eye. 
Graphical Abstract

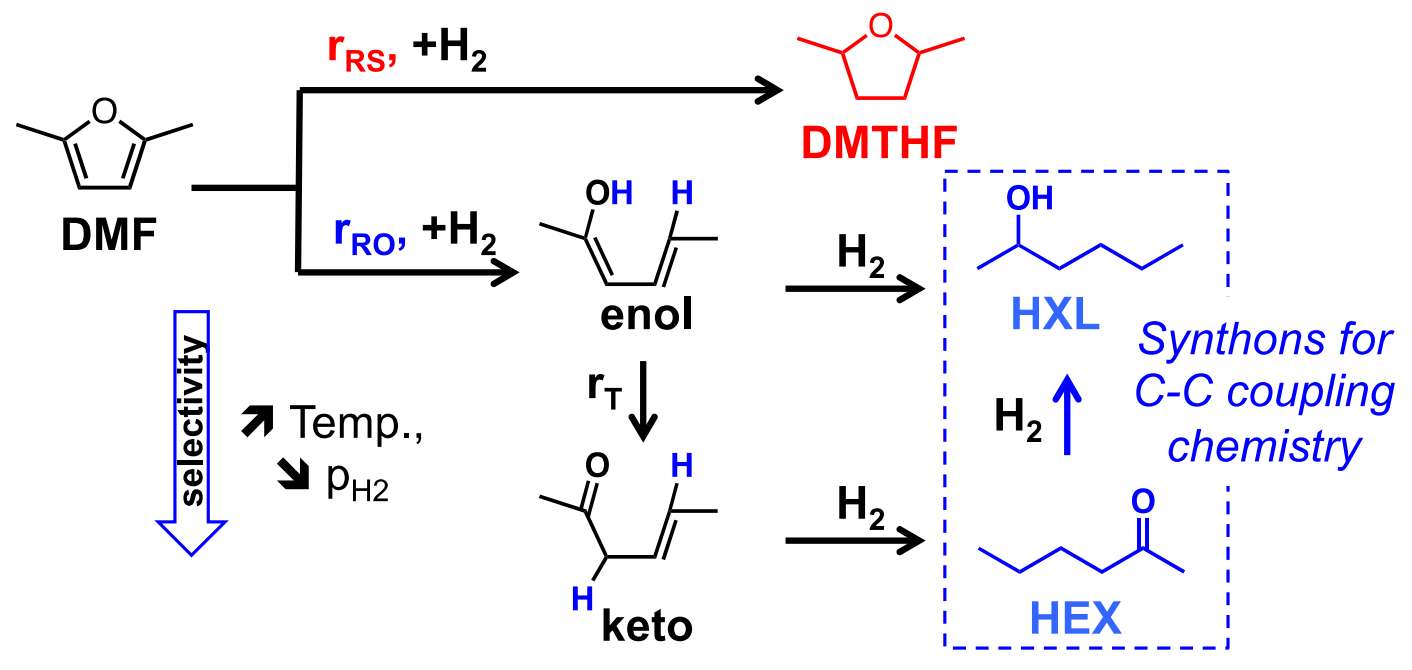

